\title{
The synthetic triterpenoids CDDO-TFEA and CDDO-Me, but not CDDO, are potent BACH1 inhibitors
}

Laura Casares ${ }^{1}$, Rita Moreno ${ }^{1}$, Maureen Higgins ${ }^{1}$, Sharadha Dayalan Naidu ${ }^{1}$, Graham Neill ${ }^{1}$, Lena Cassin ${ }^{2}$, Anders E. Kiib ${ }^{3}$, Esben B. Svenningsen ${ }^{3}$, Tadashi Honda ${ }^{4}$, Thomas B. Poulsen ${ }^{3}$, Albena T. Dinkova-Kostova ${ }^{1 *}$, David Olagnier ${ }^{2 *}$ and Laureano de la Vega ${ }^{1 *}$.

${ }^{1}$ Jacqui Wood Cancer Centre, Division of Cellular Medicine, School of Medicine, University of Dundee, UK.

${ }^{2}$ Department of Biomedicine, Health, Aarhus University, 8000, Denmark.

${ }^{3}$ Department of Chemistry, Aarhus University, Denmark

${ }^{4}$ Department of Chemistry and Institute of Chemical Biology \& Drug Discovery, Stony Brook University, Stony Brook, NY 11794-3400, USA

* Equal Senior Authorship

Corresponding Author: Laureano de la Vega (E-mail: I.delavega@dundee.ac.uk);

Short title: $\mathrm{CDDO}$-derivatives target $\mathrm{BACH} 1$

Keywords: BACH1/ HMOX1/ CDDO/NRF2 


\section{Abstract}

1 The transcription factor $\mathrm{BACH} 1$ is a potential target against a variety of chronic conditions

2 linked to oxidative stress and inflammation, and formation of cancer metastasis. However,

3 only a few BACH1 degraders/inhibitors have been described. BACH1 is a transcriptional

4 repressor of heme oxygenase 1 (HMOX1), which is positively regulated by transcription

5 factor NRF2 and is highly inducible by derivatives of the synthetic oleanane triterpenoid 2-

6 cyano-3,12-dioxooleana-1,9(11)-dien-28-oic acid (CDDO). Most of the therapeutic activities

7 of these compounds are due to their anti-inflammatory and antioxidant properties, which

8 are widely attributed to their ability to activate NRF2. However, with such a broad range of

9 action, these drugs may have other molecular targets that have not been fully identified and

10 could also be of importance for their therapeutic profile. Herein we identified BACH1 as a

11 target of CDDO-derivatives, but not CDDO. While both CDDO and CDDO-derivatives activate

12 NRF2 similarly, only CDDO-derivatives inhibit BACH1, which explains the much higher

13 potency of CDDO-derivatives as HMOX1 inducers compared with unmodified CDDO.

14 Notably, we demonstrate that CDDO-derivatives inhibit $\mathrm{BACH} 1$ via a novel mechanism that

15 reduces $\mathrm{BACH} 1$ nuclear levels while accumulating its cytoplasmic form. Altogether, our

16 study identifies CDDO-derivatives as dual KEAP1/BACH1 inhibitors, providing a rationale for

17 further therapeutic uses of these drugs.

\section{Background}

20 The synthetic oleanane triterpenoid 2-cyano-3,12-dioxooleana-1,9(11)-dien-28-oic acid

21 (CDDO) and its derivatives, including CDDO-methyl ester (CDDO-Me, also known as

22 Bardoxolone methyl) and CDDO-trifluoroethyl amide (CDDO-TFEA), are a class of

23 multifunctional drugs with anti-inflammatory and antioxidant properties that have a wide 
24 range of therapeutic uses, from neuroprotection to anticancer, in a variety of preclinical

25 models [1-5]. These compounds were first identified as inducers of heme oxygenase 1

26 (HMOX1), an inducible enzyme with potent antioxidant and anti-inflammatory properties,

27 and later as potent activators of the transcription factor NRF2 [6]. Extensive structure-

28 activity studies led to the development of the most potent NRF2 activators known to date,

29 some of which, including CDDO-Me, are currently in advanced clinical trials $[7,8]$. NRF2 is

30 largely controlled at the protein stability level, and its main regulator, KEAP1 (Kelch-like

$31 \mathrm{ECH}$-associated protein 1), is a substrate adaptor for the Cul3-based E3 ubiquitin ligase, and

32 in normal conditions, KEAP1 targets NRF2 for proteasomal degradation, keeping the levels

33 of NRF2 low in cells [9]. KEAP1 is also a sensor for electrophiles, such as CDDO and its

34 derivatives, which chemically modify cysteines in $\operatorname{KEAP1}[10,11]$ preventing it from

35 targeting NRF2 for degradation, leading to a rapid nuclear accumulation of NRF2 and

36 transcription of its target genes [9].

38 In addition to NRF2, the transcription of HMOX1 is also regulated by BACH1 (broad complex,

39 tramtrack and bric à brac and cap'n'collar homology 1), a transcription factor that competes

40 with NRF2 for binding to sequences called antioxidant response elements (AREs) within its

41 promoter region. Unlike NRF2 which activates HMOX1 transcription, BACH1 represses it [12-

42 15]. While KEAP1 inhibitors/NRF2 activators induce the expression of numerous

43 cytoprotective genes, BACH1 inhibitors/degraders activate only a limited subset of these

44 genes, although they are extremely potent at inducing HMOX1.

46 Despite their therapeutic potential [16-23], only a few BACH1 inhibitors/degraders have

47 been identified so far. The most widely used $\mathrm{BACH} 1$ degrader is hemin, a heme derivative. 
48 Hemin binds to BACH1, promoting its nuclear export and subsequent cytoplasmic

49 degradation [24-26]. Other degraders/inhibitors are the natural phytocannabinoid

50 cannabidiol [27], the synthetic compound HPP-4382 [19], and its derivatives [16], although

51 their mechanisms of action are not clear. Based on the differential effect of BACH1 versus

52 KEAP1 inhibitors, we expect drugs with dual activity, targeting both transcription factors, to

53 have broader and stronger anti-inflammatory and antioxidant properties with potentially

54 greater therapeutic value than drugs targeting either protein individually. In that regard, we

55 have recently reported a chemical derivative of cannabidiol with dual activity [28], although

56 its efficacy in vivo has not been established.

57

58 CDDO-derivatives are more potent than CDDO at inducing HMOX1 $[6,29]$ and have a better

59 therapeutic profile, although the reason for this increased activity is unclear. In this work we

60 demonstrate that CDDO derivatives (particularly CDDO-Me and CDDO-TFEA) are potent

61 BACH1 inhibitors, while CDDO is not. This dual KEAP1 and BACH1 inhibition explains their

62 enhanced potency as HMOX1 inducers and may also explain some of their superior

63 therapeutic profile.

\section{Materials and Methods}

\section{Cell culture}

67 Cells were grown in RPMI (HaCaT and HK2) or DMEM (H1299, A549) containing 10\% FBS at

6837 ? ${ }^{\circ} \mathrm{C}$ and $5 \% \mathrm{CO} 2$. LX2 cells were maintained in high glucose DMEM media with $2 \mathrm{mM} \mathrm{L-}$

69 Glutamine, without sodium pyruvate and with $2 \%$ FBS EmbryoMax $^{\mathrm{TM}}$ (Sigma-Aldrich, St.

70 Louis, MO, USA). HaCaT cells have been validated by STR profiling and were routinely tested

71 for mycoplasma. LX2 cells were obtained from SIGMA, and HK2, H1299 and A549 cells were 
72 obtained from ATCC and also tested for mycoplasma. CRISPR-edited NRF2-KO HaCaT cells

73 were produced by transfecting HaCaT cells with pLentiCRISPR-v2 (a gift from Dr Feng Zhang,

74 Addgene plasmid \#52961) containing a guide RNA directed against the exon 2 of the NFE2L2

75 locus (which encodes NRF2) (5?-TGGAGGCAAGATATAGATCT-3?). HaCaT BACH1-KO and

$76 \mathrm{HaCaT}$ NRF2-KO/BACH1-KO cells were generated by transfecting either HaCaT WT or HaCaT

77 NRF2-KO cells with two different pLentiCRISPR-v2 plasmids containing each one a guide RNA

78 against the first exon and the second exon of $\mathrm{BACH} 1$, respectively (5)-

79 CGATGTCACCATCTTTGTGG-3요, 5?-GACTCTGAGACGGACACCGA-3?]). All CRISPR-edited cell

80 lines were selected with puromycin for 2 days, cells were clonally selected by serial dilution,

81 and positive clones were identified as previously described [30]. Control cells, referred as

82 HaCaT wild type (HaCaT WT), are the pooled population of surviving cells transfected with

83 an empty pLentiCRISPRv2 vector treated with puromycin.

\section{Antibodies and reagents}

85 Antibodies against BETA-ACTIN (C-4), BACH1 (F-9) and LAMIN B2 (C-20) were obtained from

86 Santa Cruz Biotechnology (Dallas, Texas, USA). Anti-NRF2 (D1Z9C) was obtained from Cell

87 Signalling Technology (Danvers, MA, USA) and anti-HMOX1 was purchased from Biovision

88 (San Francisco, CA, USA). Antibody against ALPHA-TUBULIN was obtained from Sigma-

89 Aldrich (St. Louis, MO, USA). HRP-conjugated secondary antibodies were obtained from Life

90 Technologies (Carlsbad, California, USA). Dimethyl sulfoxide (DMSO) was from Sigma-

91 Aldrich. R,S-sulforaphane (SFN) was purchased from LKT Laboratories (St. Paul, MN, USA).

92 ( \pm -TBE-31 was synthesized as described [31, 32]. CDDO and CDDO-derivatives were

93 obtained from Cayman Chemicals (Ann Arbor, MI, USA). MG132 was obtained from Santa

94 Cruz Biotechnology; Leptomycin B from Cayman Chemicals, MLN4924 and Selinexor (KPT- 
95 330) from Selleckchem (Houston, TX, USA) and Actinomycin D and Cycloheximide from

96 Sigma.

97 Plasmids

98 BACH1-RFP, and BACH1- C435, C46, C492, C646A (Hemin resistant) -RFP were generated as

99 follows. BACH1 WT or Hemin-resistant inserts were synthesised and cloned into Plenti-CMV-

100 MCS-RFP-SV-puro. Plenti-CMV-MCS-RFP-SV-puro was a gift from Jonathan Garlick \& Behzad

101 Gerami-Naini (Addgene plasmid \# 109377; http://n2t.net/addgene:109377;

102 RRID:Addgene_109377).

103 Quantitative real time PCR (rt-qPCR)

104 RNA from cells was extracted using GeneJET RNA Purification Kit (Thermo Fisher Scientific)

105 and 500?ng of RNA per sample was reverse-transcribed to CDNA using Omniscript RT kit

106 (Qiagen) supplemented with RNase inhibitor according to the manufacturer's instructions.

107 Resulting cDNA was analysed using TaqMan Universal Master Mix II (Life Technologies,

108 Carlsbad, CA, USA) as well as corresponding Taqman probes. Gene expression was

109 determined using a QuantStudio 7 Flex qPCR machine by the comparative $\Delta \Delta C T$ method. All

110 experiments were performed at least in triplicates and data were normalized to the

111 housekeeping gene HPRT1. Taqman probes used: HPRT1 Hs02800695_m1; HMOX1

112 Hs01110250_m1; AKR1B10 Hs00252524_m1.

113 Cell lysis and western blot

114 Cells were washed and harvested in ice-cold phosphate-buffered saline (PBS). For whole cell

115 extracts, cells were lysed in RIPA buffer supplemented with phosphate and protease

116 inhibitors [50 mM Tris- $\mathrm{HCl}$ pH 7.5, $150 \mathrm{mM} \mathrm{NaCl}, 2 \mathrm{mM}$ EDTA, 1\% NP40, 0.5\% sodium

117 deoxycholate, $0.5 \mathrm{mM}$ Na3VO4, $50 \mathrm{mM} \mathrm{NaF}, 2 \mu \mathrm{g} / \mathrm{mL}$ leupeptine, $2 \mu \mathrm{g} / \mathrm{mL}$ aprotinin, 0.05

$118 \mathrm{mM}$ pefabloc]. Lysates were sonicated for $15 \mathrm{~s}$ at $20 \%$ amplitude and then cleared by 
119 centrifugation for $15 \min$ at $4{ }^{\circ} \mathrm{C}$. For subcellular fractionation, cells were resuspended in

120400 ? $\mathrm{\mu l}$ of low-salt buffer A (10?mM Hepes/KOH pH7.9, 10? $\mathrm{mM} \mathrm{KCL,} \mathrm{0.1?mM} \mathrm{EDTA,}$

1210.1 ? mM EGTA, 1?mM $\beta$-Mercaptoethanol) and after incubation for 10? ? min on ice, 10? $\mu \mathrm{l}$ of

$12210 \%$ NP-40 was added and cells were lysed by gently vortexing. The homogenate was

123 centrifuged for 10 ?

124 was collected and the pellet containing the cell nuclei was washed 4 additional times in

125 buffer $A$. The pellet containing the nuclear fraction was then resuspended in 100 ? $\mu$ l high-

126 salt buffer B (20?mM Hepes/KOH pH7.9, 400?mM NaCL, 1?mM EDTA, 1?mM EGTA, 1?mM

$127 \beta$-mercaptoethanol). The lysates were sonicated and centrifuged at 4 ? ${ }^{\circ} \mathrm{C}$ for 15 ? $\min$ at

12813,200 ? $\mathrm{rpm}$. The supernatant representing the nuclear fraction was collected. Protein

129 concentration was determined using the BCA assay (Thermo Fisher Scientific, Waltham, MA,

130 USA). Lysates were mixed with SDS sample buffer and boiled for $7 \mathrm{~min}$ at $95{ }^{\circ} \mathrm{C}$. Equal

131 amounts of protein were separated by SDS-PAGE, followed by semidry blotting to a

132 polyvinylidene difluoride membrane (Thermo Fisher Scientific). After blocking of the

133 membrane with $5 \%(w / v)$ non-fat dried milk dissolved in Tris buffered saline (TBS) with $0.1 \%$

$134 \mathrm{v} / \mathrm{v}$ Tween-20 (TBST), membranes were incubated with the primary antibodies overnight at

$1354^{\circ} \mathrm{C}$. Appropriate secondary antibodies coupled to horseradish peroxidase were detected by

136 enhanced chemiluminescence using ClarityTM Western ECL Blotting Substrate (Bio-Rad,

137 Hercules, CA, USA). Resulting protein bands were quantified and normalised to each lane's

138 loading control using the ImageStudio Lite software (LI-COR). For whole cell extracts, the

139 protein of interest was normalised against ACTIN or GADPH. LAMIN was used as an internal

140 control for nuclear extracts and TUBULIN or GADPH were used as controls for cytoplasmic

141 extracts.

\section{Cell viability assay}


143 Alamar Blue (Thermo Fisher Scientific) was used to determine cell viability after drug

144 treatment. HaCaT cells were seeded in 96-well plates to 50-60\% confluency and treated the

145 next day with the corresponding compounds for 48 hours. After treatment, Alamar Blue was

146 added to the wells (1:10 ratio) and after four hours of incubation at $37^{\circ} \mathrm{C}$ the fluorescence

147 was measured (excitation 550 and an emission at $590 \mathrm{~nm}$ ) using a microplate reader

148 (Spectramax m2). Viability was calculated relative to the DMSO treated control.

\section{Statistical analysis}

150 Experiments were repeated at least 2-5 times with multiple technical replicates to be 151 eligible for the indicated statistical analyses. Data were analysed using Graphpad Prism 152 statistical package. All results are presented as mean \pm SD unless otherwise mentioned. The 153 differences between groups were analysed using one-way ANOVA.

\section{Results}

156 CDDO-derivatives, but not CDDO, reduce BACH1 levels. We have previously shown in

157 immortalised human keratinocytes (HaCaT cells), that the classical NRF2 activator 158 sulforaphane (SFN) is a weak HMOX1 inducer (but a very good inducer of the NRF2

159 transcriptional target $A K R 1 B 10$ ), while $\mathrm{BACH} 1$ degraders such as hemin strongly induce 160 HMOX1 (in an NRF2-independent manner) without affecting AKR1B10 expression [27, 28].

161 This emphasizes that although HMOX1 has often been used as a surrogate for NRF2 activity, 162 in some cases $A K R 1 B 10$ induction might be a more appropriate reporter for NRF2 activation 163 while HMOX1 induction is a better surrogate for $\mathrm{BACH} 1$ inhibition. To answer whether the 164 observed limited effect of SFN on HMOX1 in HaCaT cells is a general phenomenon for NRF2 165 activators we compared three potent NRF2 activators (SFN, CDDO and TBE31) against a $166 \mathrm{BACH} 1$ degrader (hemin) for their ability to induce HMOX1 in these cells. As shown in figure 
167 1A, all three NRF2 activators were weak HMOX1 inducers when compared with hemin but 168 potent inducers of $A K R 1 B 10$ expression.

170 Since CDDO-Me is more potent than CDDO at inducing HMOX1 expression in some cellular

171 models, we tested whether CDDO-Me and CDDO had a differential effect on HMOX1 172 transcription in $\mathrm{HaCaT}$ cells. CDDO-Me was significantly more potent than CDDO at inducing

173 HMOX1 expression, although both compounds were equally potent at inducing $A K R 1 B 10$

174 (Fig. 1B), suggesting that their differential effect on HMOX1 must be NRF2-independent.

175 Next, we hypothesised that, in addition to activating NRF2, CDDO-Me might be targeting

176 BACH1. To test this, we compared the effect that CDDO and CDDO-Me had on BACH1 and

177 NRF2 protein levels. As shown in figure $1 \mathrm{C}, \mathrm{CDDO}-\mathrm{Me}$ - but not CDDO - reduced BACH1

178 protein levels and greatly induced HMOX1, while both compounds equally stabilised NRF2.

179 Since other CDDO-derivatives are also potent HMOX1 inducers, we hypothesised that they

180 might also reduce $\mathrm{BACH} 1$ protein levels. To test this, we compared the effect of various

181 CDDO-derivatives on BACH1 and NRF2 protein levels as well as HMOX1 and AKR1B10

182 expression. Of the derivatives tested, CDDO-TFEA and CDDO-Me were the most potent

183 compounds at reducing BACH1 levels (Suppl. Fig S1A) and at inducing HMOX1 expression

184 (Suppl. Fig S1B). All compounds (CDDO and derivatives) induced $A K R 1 B 10$ to a similar extent

185 (Suppl. Fig S1B). Based on their potency, we focused on CDDO-TFEA and CDDO-Me

186 (structures shown in Suppl. Fig S1C) and performed a time course analysis of their effect on

$187 \mathrm{BACH} 1$ levels. Our results show that $\mathrm{BACH} 1$ reduction appears to be maximal between three

188 and six hours, and that this effect is not observed at 16 hours (Fig. 1 D). Neither CDDO-TFEA

189 nor CDDO-Me reduced cell viability at the concentrations used in various cellular systems

190 (Suppl. Fig. S1D). 
192 The differential effect of CDDO and CDDO-derivatives on HMOX1 expression is due to

193 BACH1 inhibition. Reportedly, some CDDO-derivatives still increase HMOX1 protein levels in

194 the absence of NRF2 [29], although the factor responsible for that induction has not been

195 identified. To test whether in our system the differential effect of CDDO-TFEA and CDDO-Me

196 versus CDDO was dependent on NRF2, we compared wild type (WT) and NRF2-KO HaCaT

197 cells. We found that both CDDO-TFEA and CDDO-Me were more potent than CDDO at

198 inducing HMOX1 in WT cells, and a similar pattern (although with reduced fold induction)

199 was observed in NRF2-KO cells (Fig. 2A), demonstrating that the differential effect between

200 CDDO and CDDO-TFEA/Me was indeed not related to NRF2. On the other hand, AKR1B10

201 induction in WT cells was similar for the three compounds and was completely abolished in

202 the absence of NRF2 (Fig. 2B). We used a complementary approach with an immortalised

203 human proximal tubular kidney cell line (HK2) to test if the observed NRF2-independent

204 differential effect of CDDO-derivatives on HMOX1 was cell-type specific. Using CRISPR/Cas9

205 gene editing, we produced an isogenic HK2 cell line with hyperactive NRF2 that cannot be

206 further stabilised by activators (NRF2-GOF cells) (Cell line validation in Suppl. Fig S2A). In

207 this cell line, CDDO failed to induce HMOX1 any further while CDDO-Me and CDDO-TFEA still

208 potently induced HMOX1 (Suppl. Fig. S2B), confirming that this differential induction does

209 not depend on NRF2 stabilisation. In agreement with the results obtained in HaCaT cells, the

210 three compounds equally induced $A K R 1 B 10$ in WT HK2 cells but failed to induce it further in

211 NRF2-GOF HK2 cells (Suppl. Fig. S2C).

212 As $\mathrm{BACH} 1$ is a key regulator of HMOX1 expression, we hypothesised that the differential

213 effect between CDDO and CDDO-derivatives must be due to their differential activity on

$214 \mathrm{BACH} 1$, and that the strong effect of CDDO-derivatives on HMOX1 expression relates to the 
215 combination of NRF2 stabilisation and $\mathrm{BACH} 1$ reduction. To test this, we compared the

216 three compounds in BACH1-KO and in BACH1/NRF2-KO HaCaT cells. In BACH1-KO cells, the

217 differential effect between CDDO and CDDO-derivatives on HMOX1 was lost (Fig. 2C left

218 panel), suggesting that $\mathrm{BACH} 1$ is indeed responsible for that effect (comparison between

219 Fig. 2C and 2A), and that NRF2 (or another factor) might be responsible for the remaining

220 observed induction. In fact, in double BACH1/NRF2-KO cells the effect of the compounds on

221 HMOX1 expression was largely abolished, highlighting the relevance of both factors

222 regulating HMOX1 (Fig. 2C right panel).

224 CDDO-derivatives reduce BACH1 nuclear levels while accumulating cytoplasmic BACH1

225 levels in a NRF2-independent manner. Our results demonstrate that CDDO-derivatives, but

226 not $\mathrm{CDDO}$, reduce the levels of $\mathrm{BACH1}$, and that this reduction is responsible for their

227 differential effect on HMOX1 expression. However, the reduction of BACH1 levels was less

228 than expected based on the strong HMOX1 induction (which was similar to that observed

229 with the potent BACH1 degrader hemin). Furthermore, although CDDO-derivatives were still

230 robust inducers of HMOX1 in other cell lines (such as HK2 cells, the lung cancer cells H1299

231 and A549, or the human hepatic stellate cell line LX2), in contrast to HaCaT cells (Fig. 1B),

232 they did not affect the BACH1 levels (Suppl. Fig. S3A-S3D), which was intriguing. As some of

233 the compounds that target $\mathrm{BACH} 1$ for degradation do so by first inducing its nuclear export

234 [25], we wondered whether CDDO-derivatives might affect the balance between

235 nuclear/cytoplasmic BACH1 and whether the compound effect could be on nuclear BACH1

236 (the active pool). Indeed, while in HK2, LX2, H1299 and A549 cells the effect of CDDO-

237 derivatives on total BACH1 (whole cell extract) was insignificant (Suppl. Fig. S3A-S3D), by

238 using subcellular fractionation we observed that CDDO-Me and CDDO-TFEA significantly 
239 reduced nuclear BACH1 while increasing its cytoplasmic levels (Fig. 3A-3D). This explains the

240 apparent lack of effect on total BACH1 levels (as the cytoplasmic accumulation would mask

241 its nuclear reduction) and the strong HMOX1 induction (as nuclear BACH1 represents the

242 transcriptionally active pool).

244 Additionally, as these compounds are potent NRF2 activators and NRF2 induces BACH1

245 expression [33, 34], we tested whether NRF2 was necessary for the effect of CDDO-

246 derivatives on $\mathrm{BACH} 1$ nuclear and cytoplasmic levels. To do this, we performed time course

247 experiments in WT and NRF2-KO HaCaT cells. The absence of NRF2 did not impair the

248 reduction in nuclear BACH1 nor its cytoplasmic accumulation (comparison between Suppl

249 Fig. S3E and S3F), strongly suggesting that NRF2 is not required for either of these effects. In

250 agreement, potent NRF2 activators such as CDDO or TBE31 did not induce BACH1

251 cytoplasmic accumulation or promote its nuclear reduction (Suppl Fig. S3G).

252

253 How are CDDO-derivatives affecting BACH1 levels? The nuclear reduction and cytoplasmic

254 accumulation of $\mathrm{BACH} 1$ in response to CDDO-TFEA/Me could be explained in different ways:

255 1- The two effects are not linked: e.g. CDDO-derivatives induce BACH1 nuclear degradation

256 and independently, BACH1 cytoplasmic accumulation, either by increasing the protein

257 stability or the transcript levels of BACH1.

258 2- The two effects are linked: e.g. CDDO-derivatives affect the nuclear export of BACH1.

260 We next tested these two possible explanations:

261 Is BACH1 protein stability affected by the CDDO-derivatives? The two main pathways

262 controlling protein degradation are the ubiquitin-proteasome system and autophagy. To 
263 study the involvement of the ubiquitin-proteasome system we used MG132 (proteasome

264 inhibitor) and MLN 4924 (an inhibitor of NEDD8 activating enzyme, which acts by inhibiting

265 all Cullin RING ligases). Although both inhibitors increased the basal levels of BACH1, neither

266 of them abolished the effect of CDDO-TFEA/Me on BACH1 (Fig. 4A), suggesting that

267 degradation of $\mathrm{BACH} 1$ via the proteasome is not the main mechanism by which the CDDO-

268 derivatives reduce levels of $\mathrm{BACH} 1$. To address the potential role of autophagy, we used the

269 autophagy inhibitor bafilomycin A1, which did not impair the effect of CDDO-Me/TFEA on

270 BACH1 protein levels (Suppl Fig. S4A).

271 Hemin (the best-characterised $\mathrm{BACH} 1$ degrader) binds to $\mathrm{BACH} 1$, promoting its proteasomal

272 degradation, and thus our results suggest that CDDO-derivatives and hemin might have

273 different mechanisms of action. To address this, we reconstituted BACH1-KO cells with

274 either BACH1-WT or a BACH1 hemin-resistant mutant, in which four cysteines in the haem-

275 binding site were mutated to alanine (Hemin-resistant) [25, 35]. Although both hemin and

276 the CDDO-derivatives efficiently reduced nuclear levels of BACH1-WT, only CDDO-TFEA/Me

277 reduced the levels of the hemin-resistant BACH1 mutant (Fig. 4B). These results further

278 confirm that the mechanism of $\mathrm{BACH} 1$ reduction by CDDO-TFEA/Me is different from that of

279 hemin.

280 Is BACH1 transcription affected by the CDDO-derivatives? As BACH1 protein stability did not

281 seem to be affected by CDDO-TFEA/Me, we tested if BACH1 transcriptional regulation was

282 responsible for its cytoplasmic accumulation. To test this, we used compounds to inhibit

283 either protein synthesis (cycloheximide, a protein synthesis inhibitor) or transcription

284 (actinomycin D, a DNA-directed RNA synthesis inhibitor). Neither of these inhibitors blocked

285 BACH1 nuclear reduction or its cytoplasmic accumulation in response to CDDO-TFEA/Me 
286 (Suppl Fig. S4B), suggesting that synthesis of new proteins (and their transcription) is not

287 needed for the effect of the CDDO-derivatives on BACH1.

288 Is BACH1 nuclear export affected by the CDDO-derivatives? So far, our results showed that

289 neither transcriptional regulation nor protein degradation are mechanisms responsible for

290 the effect of CDDO-TFEA/Me, suggesting that the CDDO-derivatives might be reducing

291 nuclear BACH1 and accumulating its cytoplasmic pool via a nuclear export mechanism.

292 While small molecules (20-40 kD) can passively diffuse between the nucleus and the 293 cytoplasm, transport of larger molecules such as proteins involves signal-dependent

294 mechanisms. Many nuclear export substrates contain a nuclear export signal (NES) that

295 binds the export receptor CRM1 (exportin 1/Xpo1), which is sensitive to inhibitors such as

296 leptomycin B and selinexor. However, not all proteins that shuttle between the nucleus and

297 cytoplasm use CRM1 to do so, and CRM1-independent nuclear export pathways have been

298 identified [36-40]. To address whether the changes in nuclear and cytoplasmic BACH1 in

299 response to CDDO-TFEA/Me are related to a CRM1-dependent nuclear export mechanism,

300 we tested the effect of two CRM1 inhibitors (leptomycin B and selinexor) (Suppl. Fig S4C).

301 Although both inhibitors induced a basal nuclear accumulation of BACH1, as expected,

302 neither of them abolished its nuclear reduction nor its cytoplasmic accumulation in

303 response to CDDO-TFEA/Me. Overall, our data suggest that CDDO-derivatives induce BACH1

304 nuclear export in a CRM1-independent manner.

306 Discussion

307 Our results demonstrate that CDDO-derivatives - but not CDDO - inhibit BACH1, explaining 308 their greater potency as HMOX1 inducers in comparison with CDDO. Although we did not 309 identify the mechanism(s) responsible for the ability of CDDO-derivatives to reduce nuclear 
$310 \mathrm{BACH} 1$ levels, our data show that neither the proteasome nor the nuclear export receptor

311 CRM1 are involved, demonstrating that CDDO-derivatives use a mechanism different from

312 the one used by hemin. This highlights the need to better understand the mechanisms

313 controlling $\mathrm{BACH} 1$ regulation. Additionally, the differential effect observed in the levels of

314 nuclear and cytoplasmic BACH1 shows that nuclear reduction of $\mathrm{BACH} 1$ (without further

315 cytoplasmic degradation) is sufficient for a strong HMOX1 induction. This should be taken

316 into consideration in the design of screening strategies to identify BACH1 inhibitors, as only

317 looking at total BACH1 levels in cells could be misleading. It would be interesting to address

318 whether the accumulation of cytoplasmic BACH1 may have other functions that are

319 unrelated to its well-characterized role as transcriptional regulator.

321 Our data demonstrate that both CDDO-TFEA and CDDO-Me are very potent dual KEAP1 and

322 BACH1 inhibitors, which could explain some of their therapeutic benefits. Importantly our

323 study provides a rationale for their potential clinical development for conditions affected by

324 BACH1, such as bone destructive diseases [16], non-alcoholic steatohepatitis [22],

325 atherosclerosis [23], insulin resistance [20], coronary artery disease [41], aging related

326 conditions [17] and tumour metastasis [33, 34, 42-46].

\section{FUNDING}

This work was supported by the Medical Research Institute of the University of Dundee, Cancer Research UK (C52419/A22869 and C20953/A18644) (LV and ADK), Tenovus Scotland (T18/07) (LC) and Medical Research Scotland (PhD-50058-2019). DO was supported by the Lundbeck Foundation (R335-2019-2138), Kræftens Bekæmpelse (R279-A16218), the 
Brødrene Hartman Fond, the Hørslev Fond, the fabrikant Einer Willumsens mindelegat, and the Eva og Henry Fraenkels Mindefond.

\section{AUTHORS CONTRIBUTION}

LC, RM, MH, SDN, GN, AEK, EBS, WL and LC conducted the experiments and were responsible for initial data analysis, figure preparation and statistical analysis. TH and TBP provided resources and technical expertise. LV, DO and ADK had a leading contribution in the design of the study, and an active role in the discussion and interpretation of the whole dataset. LV wrote the original draft of the manuscript. ADK, DO and LC reviewed and edited the manuscript. Funding acquisition LV, DO and ADK. All the authors take full responsibility for the work.

\section{DECLARATION OF INTERESTS}

ADK is a member of the Scientific Advisory Board of Evgen Pharma, and a consultant for Aclipse Therapeutics.

\section{References}

1. Wang Y, Porter WW, Suh N, Honda T, Gribble GW, Leesnitzer LM, et al. A synthetic triterpenoid, 2-cyano-3,12-dioxooleana-1,9-dien-28-oic acid (CDDO), is a ligand for the peroxisome proliferator-activated receptor gamma. Mol Endocrinol. 2000;14(10):1550-6.

2. Konopleva M, Tsao T, Ruvolo P, Stiouf I, Estrov Z, Leysath CE, et al. Novel triterpenoid CDDO-Me is a potent inducer of apoptosis and differentiation in acute myelogenous leukemia. Blood. 2002;99(1):326-35.

3. Liby K, Royce DB, Williams CR, Risingsong R, Yore MM, Honda T, et al. The synthetic triterpenoids CDDO-methyl ester and CDDO-ethyl amide prevent lung cancer induced by vinyl carbamate in A/J mice. Cancer Res. 2007;67(6):2414-9.

4. Sun K, Li M, Konopleva M, Konoplev S, Stephens LC, Kornblau SM, et al. The synthetic triterpenoid, CDDO, suppresses alloreactive $T$ cell responses and reduces murine early acute graft-versus-host disease mortality. Biol Blood Marrow Transplant. 2007;13(5):521-9. 
5. Tran TA, McCoy MK, Sporn MB, Tansey MG. The synthetic triterpenoid CDDO-methyl ester modulates microglial activities, inhibits TNF production, and provides dopaminergic neuroprotection. J Neuroinflammation. 2008;5:14.

6. Liby $K$, Hock $T$, Yore $M M$, Suh $N$, Place $A E$, Risingsong $R$, et al. The synthetic triterpenoids, CDDO and CDDO-imidazolide, are potent inducers of heme oxygenase- 1 and Nrf2/ARE signaling. Cancer Res. 2005;65(11):4789-98.

7. Cuadrado A, Rojo Al, Wells G, Hayes JD, Cousin SP, Rumsey WL, et al. Therapeutic targeting of the NRF2 and KEAP1 partnership in chronic diseases. Nat Rev Drug Discov. 2019;18(4):295-317.

8. Sporn MB, Liby KT, Yore MM, Fu L, Lopchuk JM, Gribble GW. New synthetic triterpenoids: potent agents for prevention and treatment of tissue injury caused by inflammatory and oxidative stress. J Nat Prod. 2011;74(3):537-45.

9. Yamamoto M, Kensler TW, Motohashi H. The KEAP1-NRF2 System: a Thiol-Based Sensor-Effector Apparatus for Maintaining Redox Homeostasis. Physiol Rev. 2018;98(3):1169-203.

10. Dayalan Naidu S, Muramatsu A, Saito R, Asami S, Honda T, Hosoya T, et al. C151 in KEAP1 is the main cysteine sensor for the cyanoenone class of NRF2 activators, irrespective of molecular size or shape. Sci Rep. 2018;8(1):8037.

11. Dinkova-Kostova AT, Liby KT, Stephenson KK, Holtzclaw WD, Gao X, Suh N, et al. Extremely potent triterpenoid inducers of the phase 2 response: correlations of protection against oxidant and inflammatory stress. Proc Natl Acad Sci U S A. 2005;102(12):4584-9.

12. Sun J, Hoshino H, Takaku K, Nakajima O, Muto A, Suzuki H, et al. Hemoprotein Bach1 regulates enhancer availability of heme oxygenase-1 gene. EMBO J. 2002;21(19):5216-24.

13. Dhakshinamoorthy S, Jain AK, Bloom DA, Jaiswal AK. Bach1 competes with Nrf2 leading to negative regulation of the antioxidant response element (ARE)-mediated $\mathrm{NAD}(\mathrm{P}) \mathrm{H}$ :quinone oxidoreductase 1 gene expression and induction in response to antioxidants. J Biol Chem. 2005;280(17):16891-900.

14. Shan Y, Lambrecht RW, Donohue SE, Bonkovsky HL. Role of Bach1 and Nrf2 in upregulation of the heme oxygenase-1 gene by cobalt protoporphyrin. FASEB J. 2006;20(14):2651-3.

15. Reichard JF, Motz GT, Puga A. Heme oxygenase-1 induction by NRF2 requires inactivation of the transcriptional repressor BACH1. Nucleic Acids Res. 2007;35(21):7074-86.

16. Wada S, Kanzaki H, Katsumata Y, Yamaguchi Y, Narimiya T, Attucks OC, et al. Bach1 Inhibition Suppresses Osteoclastogenesis via Reduction of the Signaling via Reactive Oxygen Species by Reinforced Antioxidation. Front Cell Dev Biol. 2020;8:740.

17. Zhang H, Zhou L, Davies KJA, Forman HJ. Silencing Bach1 alters aging-related changes in the expression of Nrf2-regulated genes in primary human bronchial epithelial cells. Arch Biochem Biophys. 2019;672:108074.

18. Tian X, Cong F, Guo H, Fan J, Chao G, Song T. Downregulation of Bach1 protects osteoblasts against hydrogen peroxide-induced oxidative damage in vitro by enhancing the activation of Nrf2/ARE signaling. Chem Biol Interact. 2019;309:108706. 
19. Attucks OC, Jasmer KJ, Hannink M, Kassis J, Zhong Z, Gupta S, et al. Induction of heme oxygenase I (HMOX1) by HPP-4382: a novel modulator of Bach1 activity. PLoS One. 2014;9(7):e101044.

20. Kondo K, Ishigaki Y, Gao J, Yamada T, Imai J, Sawada S, et al. Bach1 deficiency protects pancreatic beta-cells from oxidative stress injury. Am J Physiol Endocrinol Metab. 2013;305(5):E641-8.

21. Harusato A, Naito Y, Takagi T, Uchiyama K, Mizushima K, Hirai Y, et al. BTB and CNC homolog 1 (Bach1) deficiency ameliorates TNBS colitis in mice: role of $\mathrm{M} 2$ macrophages and heme oxygenase-1. Inflamm Bowel Dis. 2013;19(4):740-53.

22. Inoue M, Tazuma S, Kanno K, Hyogo H, Igarashi K, Chayama K. Bach1 gene ablation reduces steatohepatitis in mouse MCD diet model. J Clin Biochem Nutr. 2011;48(2):161-6.

23. Watari Y, Yamamoto Y, Brydun A, Ishida T, Mito S, Yoshizumi M, et al. Ablation of the bach1 gene leads to the suppression of atherosclerosis in bach1 and apolipoprotein $E$ double knockout mice. Hypertens Res. 2008;31(4):783-92.

24. Sun J, Brand M, Zenke $Y$, Tashiro S, Groudine M, Igarashi K. Heme regulates the dynamic exchange of Bach1 and NF-E2-related factors in the Maf transcription factor network. Proc Natl Acad Sci U S A. 2004;101(6):1461-6.

25. Suzuki H, Tashiro S, Hira S, Sun J, Yamazaki C, Zenke $Y$, et al. Heme regulates gene expression by triggering Crm1-dependent nuclear export of Bach1. EMBO J. 2004;23(13):2544-53.

26. Zenke-Kawasaki Y, Dohi Y, Katoh Y, Ikura T, Ikura M, Asahara T, et al. Heme induces ubiquitination and degradation of the transcription factor Bach1. Mol Cell Biol. 2007;27(19):6962-71.

27. Casares L, Garcia V, Garrido-Rodriguez M, Millan E, Collado JA, Garcia-Martin A, et al. Cannabidiol induces antioxidant pathways in keratinocytes by targeting BACH1. Redox Biol. 2020;28:101321.

28. Casares L, Unciti-Broceta JD, Prados ME, Caprioglio D, Mattoteia D, Higgins $M$, et al. Isomeric O-methyl cannabidiolquinones with dual BACH1/NRF2 activity. Redox Biol. 2020;37:101689.

29. To C, Ringelberg CS, Royce DB, Williams CR, Risingsong R, Sporn MB, et al. Dimethyl fumarate and the oleanane triterpenoids, CDDO-imidazolide and CDDO-methyl ester, both activate the Nrf2 pathway but have opposite effects in the $A / J$ model of lung carcinogenesis. Carcinogenesis. 2015;36(7):769-81.

30. Torrente L, Sanchez C, Moreno R, Chowdhry S, Cabello P, Isono K, et al. Crosstalk between NRF2 and HIPK2 shapes cytoprotective responses. Oncogene. 2017;36(44):620412.

31. Saito A, Zheng SQ, Takahashi M, Li W, Ojima I, Honda T. An Improved Synthesis of a Hydroxymethyl Tricyclic Ketone from Cyclohexanone, the Key Processes for the Synthesis of a Highly Potent Anti-inflammatory and Cytoprotective Agent. Synthesis-Stuttgart. 2013;45(23):3251-4. 
32. Honda T, Yoshizawa H, Sundararajan C, David E, Lajoie MJ, Favaloro FG, Jr., et al. Tricyclic compounds containing nonenolizable cyano enones. A novel class of highly potent anti-inflammatory and cytoprotective agents. J Med Chem. 2011;54(6):1762-78.

33. Wiel C, Le Gal K, Ibrahim MX, Jahangir CA, Kashif M, Yao H, et al. BACH1 Stabilization by Antioxidants Stimulates Lung Cancer Metastasis. Cell. 2019;178(2):330-45 e22.

34. Lignitto L, LeBoeuf SE, Homer H, Jiang S, Askenazi M, Karakousi TR, et al. Nrf2 Activation Promotes Lung Cancer Metastasis by Inhibiting the Degradation of Bach1. Cell. 2019;178(2):316-29 e18.

35. Ogawa K, Sun J, Taketani S, Nakajima O, Nishitani C, Sassa S, et al. Heme mediates derepression of Maf recognition element through direct binding to transcription repressor Bach1. EMBO J. 2001;20(11):2835-43.

36. Wiechens N, Fagotto F. CRM1- and Ran-independent nuclear export of beta-catenin. Curr Biol. 2001;11(1):18-27.

37. Vajjhala PR, Macmillan E, Gonda T, Little M. The Wilms' tumour suppressor protein, WT1, undergoes CRM1-independent nucleocytoplasmic shuttling. FEBS Lett. 2003;554(12):143-8.

38. Saijou E, Itoh T, Kim KW, lemura S, Natsume T, Miyajima A. Nucleocytoplasmic shuttling of the zinc finger protein EZI Is mediated by importin-7-dependent nuclear import and CRM1-independent export mechanisms. J Biol Chem. 2007;282(44):32327-37.

39. Thomas $M$, Lischka $P$, Muller $R$, Stamminger $T$. The cellular DExD/H-box RNAhelicases UAP56 and URH49 exhibit a CRM1-independent nucleocytoplasmic shuttling activity. PLoS One. 2011;6(7):e22671.

40. Huang C, Jiang JY, Chang SC, Tsay YG, Chen MR, Chang MF. Nuclear export signalinteracting protein forms complexes with lamin A/C-Nups to mediate the CRM1independent nuclear export of large hepatitis delta antigen. J Virol. 2013;87(3):1596-604.

41. von Scheidt $M$, Zhao $Y$, de Aguiar Vallim TQ, Che N, Wierer M, Seldin MM, et al. Transcription Factor MAFF (MAF Basic Leucine Zipper Transcription Factor F) Regulates an Atherosclerosis Relevant Network Connecting Inflammation and Cholesterol Metabolism. Circulation. 2021;143(18):1809-23.

42. Sato $M$, Matsumoto $M$, Saiki $Y$, Alam $M$, Nishizawa $H$, Rokugo $M$, et al. BACH1 Promotes Pancreatic Cancer Metastasis by Repressing Epithelial Genes and Enhancing Epithelial-Mesenchymal Transition. Cancer Res. 2020;80(6):1279-92.

43. Han W, Zhang Y, Niu C, Guo J, Li J, Wei X, et al. BTB and CNC homology 1 (Bach1) promotes human ovarian cancer cell metastasis by HMGA2-mediated epithelialmesenchymal transition. Cancer Lett. 2019;445:45-56.

44. Shajari N, Davudian S, Kazemi T, Mansoori B, Salehi S, Khaze Shahgoli V, et al. Silencing of $\mathrm{BACH} 1$ inhibits invasion and migration of prostate cancer cells by altering metastasis-related gene expression. Artif Cells Nanomed Biotechnol. 2018;46(7):1495-504.

45. Davudian S, Shajari N, Kazemi T, Mansoori B, Salehi S, Mohammadi A, et al. BACH1 silencing by siRNA inhibits migration of HT-29 colon cancer cells through reduction of metastasis-related genes. Biomed Pharmacother. 2016;84:191-8. 
bioRxiv preprint doi: https://doi.org/10.1101/2021.10.29.466411; this version posted October 29, 2021. The copyright holder for this preprint (which was not certified by peer review) is the author/funder, who has granted bioRxiv a license to display the preprint in perpetuity. It is made available under aCC-BY 4.0 International license.

46. Liang $\mathrm{Y}, \mathrm{Wu} \mathrm{H}$, Lei R, Chong RA, Wei $\mathrm{Y}$, Lu X, et al. Transcriptional network analysis identifies $\mathrm{BACH} 1$ as a master regulator of breast cancer bone metastasis. J Biol Chem. 2012;287(40):33533-44. 


\section{A}

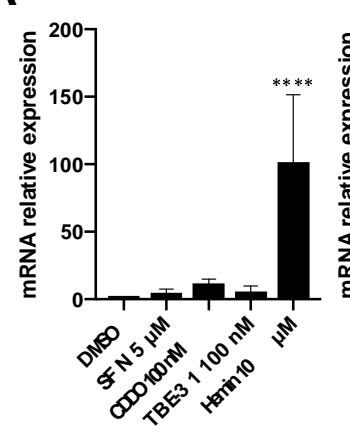

C
AKR1B10

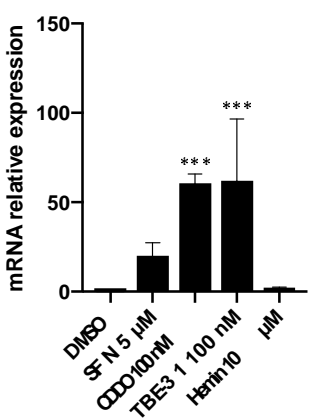

B

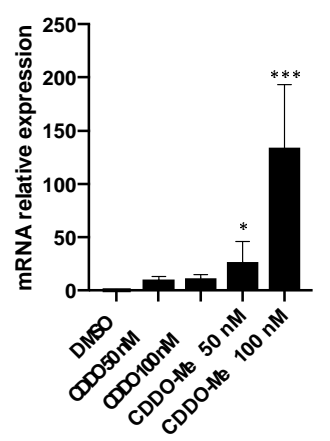

AKR1B10

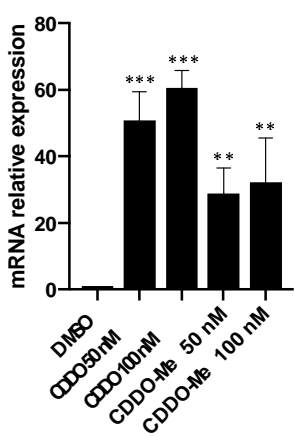

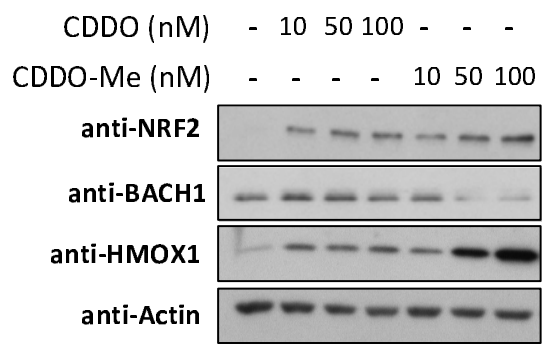

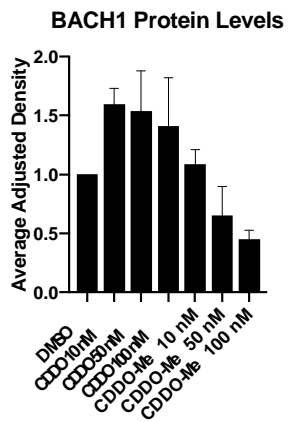

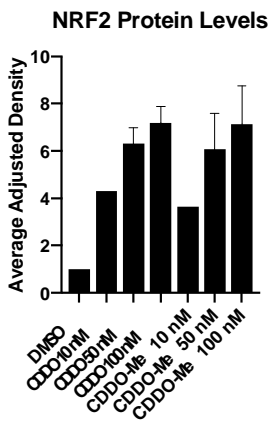

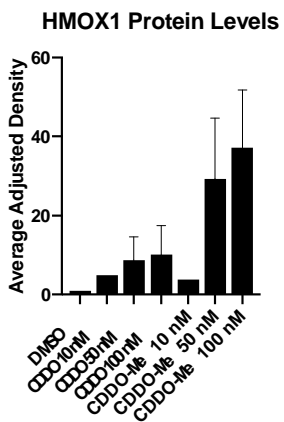

D
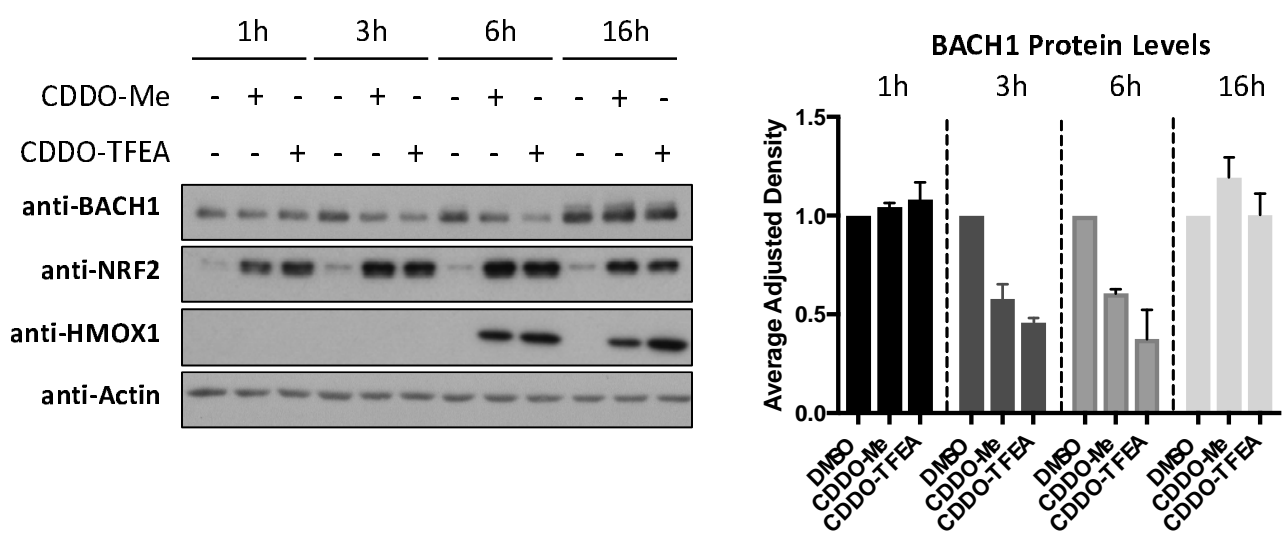

Figure 1

Figure 1. CDDO derivatives, but not CDDO, reduce BACH1 levels (A) HaCaT cells were treated with either DMSO $(0.1 \%, v / v)$, SFN $(5 \mu \mathrm{M})$, CDDO (100 nM), TBE-31 (100 nM) or Hemin $(10 \mu \mathrm{M})$ for $16 \mathrm{~h}$. Cells were lysed and mRNA levels of HMOX1 and AKR1B10 were analysed by qRT-PCR, using HPRT1 as a housekeeping gene. (B) As in A, but HaCaT cells were 
treated with either DMSO $(0.1 \%, v / v)$ or increasing concentrations of CDDO or CDDO-Me. After 16 hours cells were harvested and lysed and mRNA levels of HMOX1 and AKR1B10 were analysed by real-time qPCR. Data were normalised using HPRT1 as an internal control $(n=3)$ and are expressed relative to the DMSO treated sample. (C) HaCaT cells were treated with DMSO $(0.1 \%, v / v)$ or increasing concentrations of CDDO or CDDO-Me. Five hours later, cells were harvested and lysed. Protein levels of NRF2, BACH1, HMOX1 and ACTIN were analysed by Western Blot. Left panel shows a representative blot and right panels show quantification of NRF2 and HMOX1 protein levels against the loading control. Data represent means $\pm S D(n=3)$ and are expressed relative to the DMSO-treated samples. (D) HaCaT cells were treated with either DMSO $(0.1 \%, v / v)$, CDDO-Me (100 nM) or CDDO-TFEA (100 nM) for $1 \mathrm{~h}, 3 \mathrm{~h}, 6 \mathrm{~h}$ or $16 \mathrm{~h}$. Cells were harvested, lysed and analysed for the levels of the indicated proteins. Left panel is a representative blot; right panels are the quantification of BACH1 levels $(n=3)$. Data are expressed relative to the DMSO-treated samples for each time point and were normalized against their respective loading controls (DMSO sample for each time point set to 1$) .{ }^{*} \mathrm{P} \leq 0.05,{ }^{*} * \mathrm{P} \leq 0.01,{ }^{* * * P} \leq 0.001, * * * * \mathrm{P} \leq 0.0001$. 

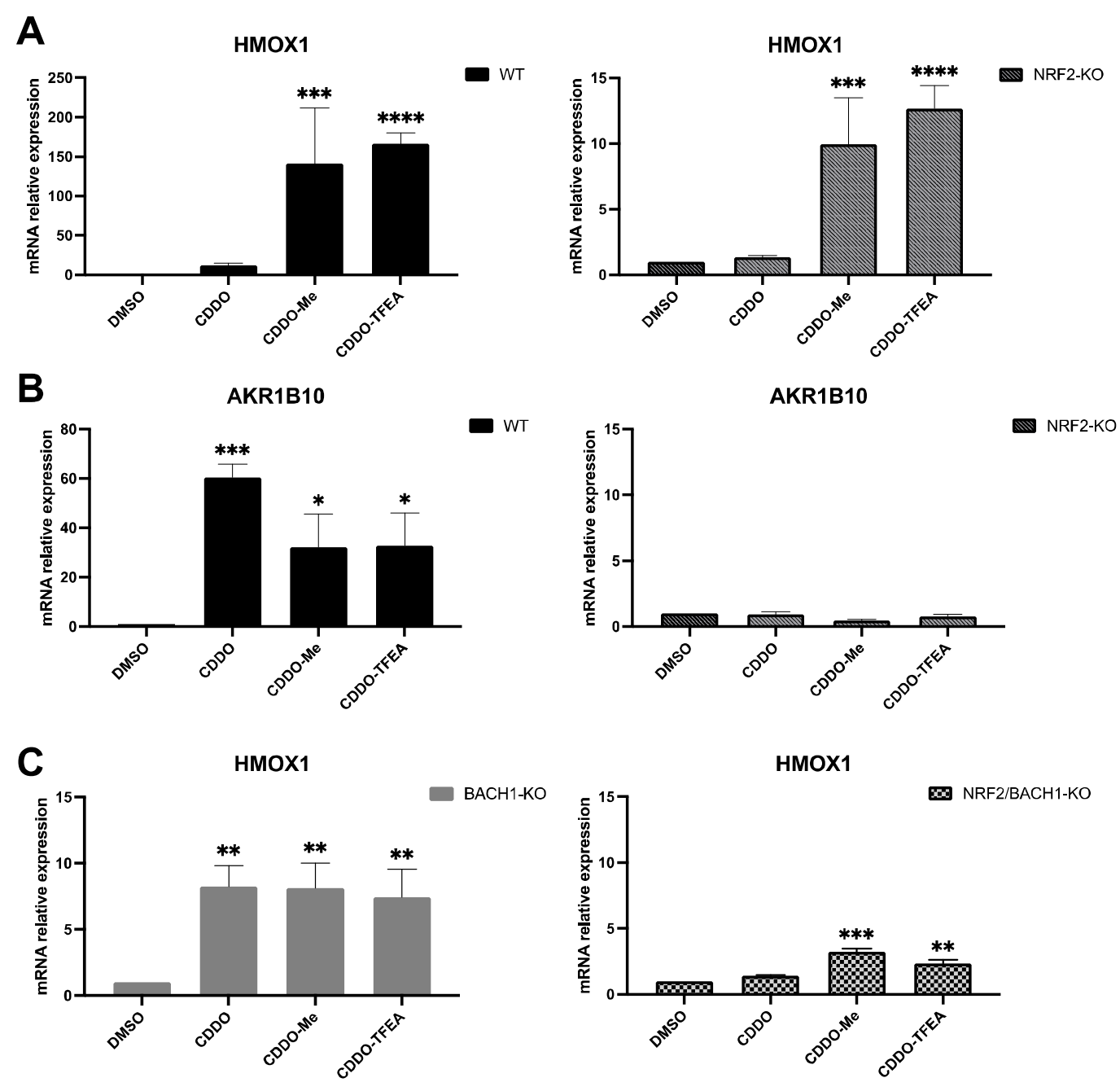

Figure 2

Figure 2. The differential effect of CDDO and CDDO/TFEA on HMOX1 is BACH1-dependent

and NRF2-independent. (A,B) HaCaT WT or NRF2-KO cells were treated with either DMSO (0.1\%, v/v), CDDO (100 nM), CDDO-Me (100 nM) or CDDO-TFEA (100 nM) for 16h. Samples were collected and mRNA levels of $H M O X 1(\mathrm{~A})$ and $A K R 1 B 10(\mathrm{~B})$ were analysed via real-time qPCR, using HPRT1 as an internal control. Data are expressed relative to the DMSO-treated samples in each cell line (DMSO in WT and NRF2-KO cells set to 1). (C) HaCaT BACH1-KO and HaCaT NRF2/BACH1-KO cells were treated as above. Levels of HMOX1 were analysed by qRT-PCR as previously described. HMOX1 levels in the DMSO samples of each cell line were 
bioRxiv preprint doi: https://doi.org/10.1101/2021.10.29.466411; this version posted October 29, 2021. The copyright holder for this preprint (which was not certified by peer review) is the author/funder, who has granted bioRxiv a license to display the preprint in perpetuity. It is made available under aCC-BY 4.0 International license.

set to 1 and the rest of the data are expressed relative to their corresponding DMSO sample. $* \mathrm{P} \leq 0.05, * * \mathrm{P} \leq 0.01, * * * \mathrm{P} \leq 0.001, * * * * \mathrm{P} \leq 0.0001$ 

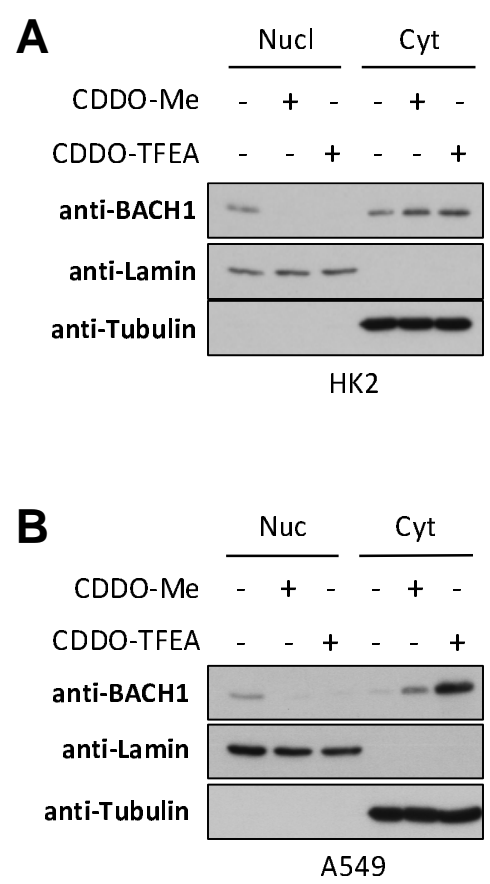

C

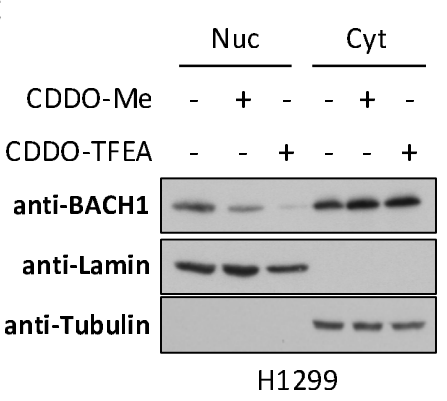

Nuclear BACH1

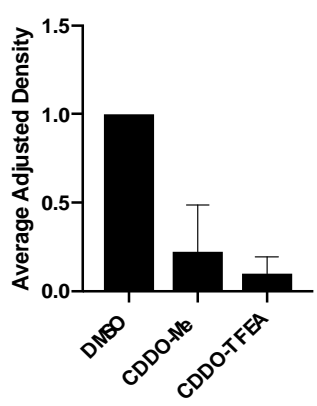

Nuclear BACH1

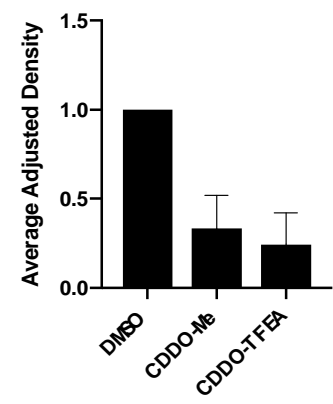

Nuclear BACH1

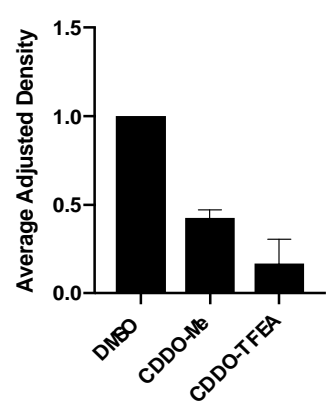

Cytoplasmic BACH1

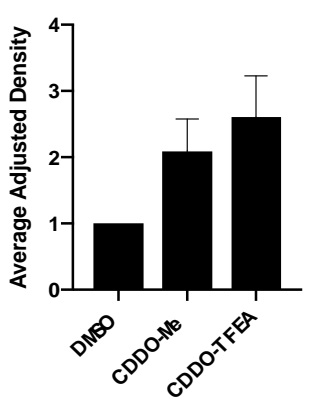

Cytoplasmic BACH1



Cytoplasmic BACH1

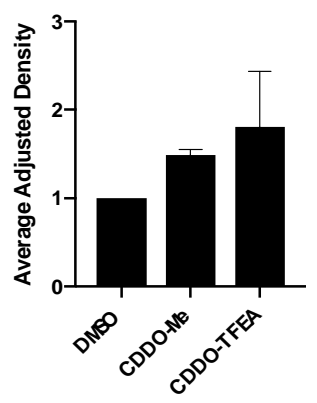

D

Nucleus

Cytoplasm

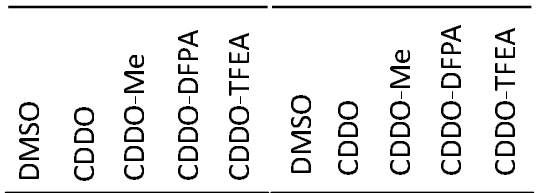

anti-BACH1

anti-LMNB2

anti-GADPH

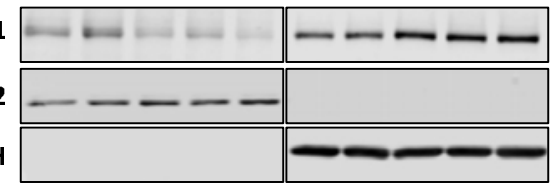

LX2

Nuclear BACH1 Cytoplasmic BACH1
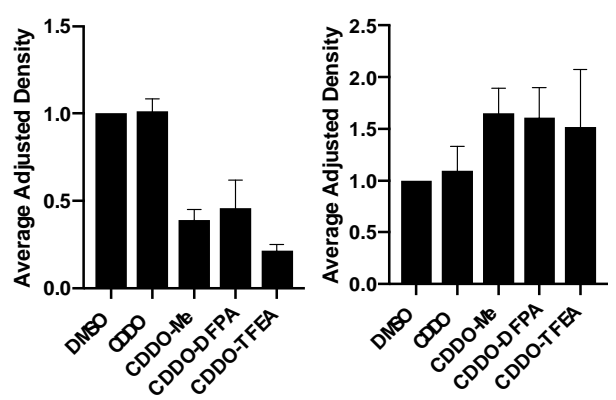

Figure 3

Figure 3. CDDO-derivatives reduce nuclear BACH1 levels while increasing cytoplasmic

BACH1 levels. (A-D) HK2 (A), A549 (B), H1299 (C) or LX2 (D) cells were treated with DMSO 
(0.1\%, v/v), CDDO-Me (100 nM) or CDDO-TFEA (100 nM). Six hours later cells were harvested and subcellular fractionation was performed. BACH1 protein levels were analysed via western blot. Panels on the left show a representative blot; panels on the right are the corresponding $\mathrm{BACH} 1$ nuclear and cytoplasmic quantifications, which were normalised against their internal control (i.e., LAMIN for nuclear and TUBULIN for cytoplasmic levels). Data represent means $\pm S D(n=3)$ and are expressed relative to the DMSO-treated samples. 

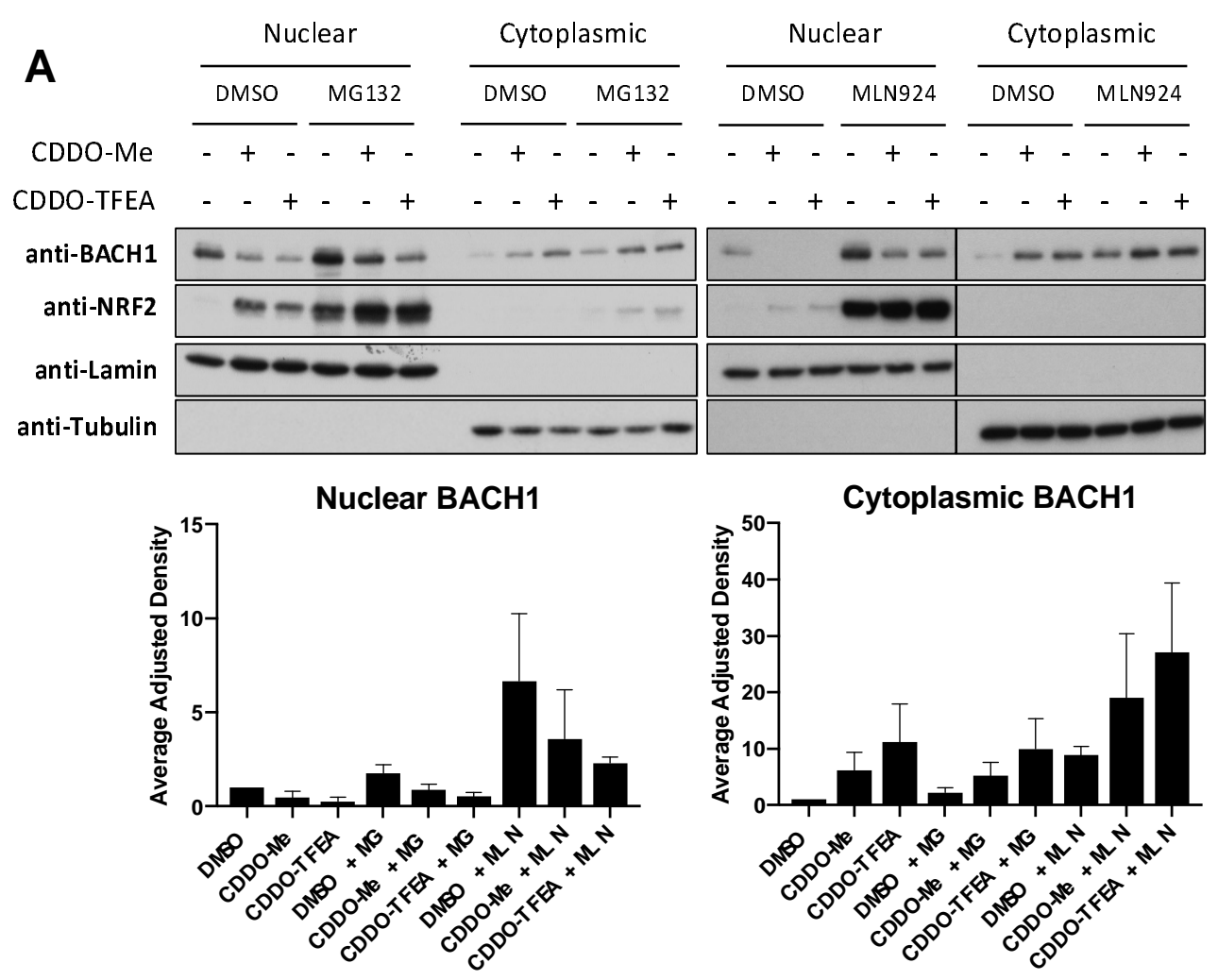

B
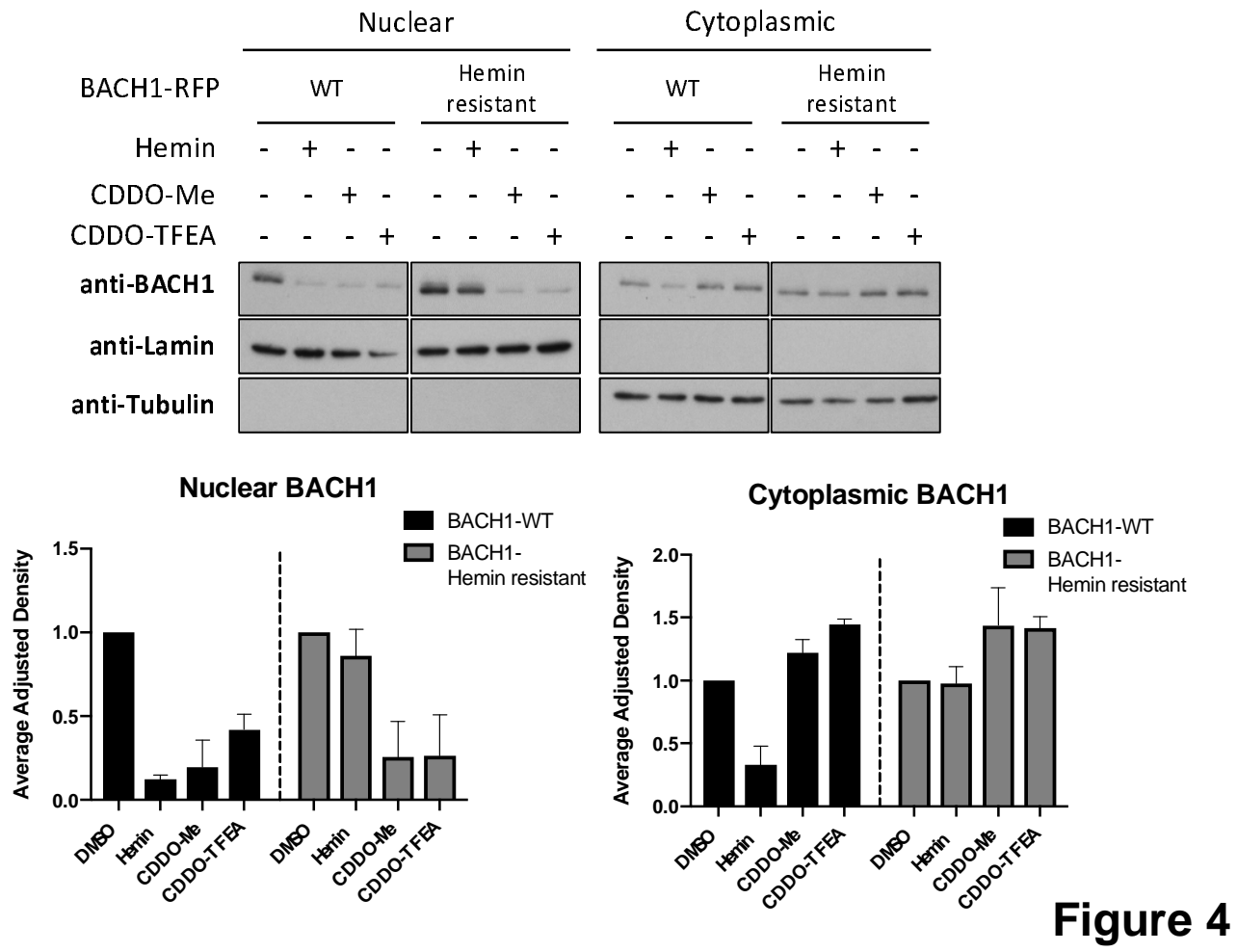

Figure 4. CDDO-Me/TFEA affects BACH1 levels in a proteasome independent manner and

have a mechanism of action different than hemin. (A) HaCaT cells were incubated with 
either DMSO $(0.1 \%, v / v)$, MG132 $(10 \mu \mathrm{M})$ or MLN924 $(2 \mu \mathrm{M})$ for one hour. After that, either DMSO (-), CDDO-Me (100 nM) or CDDO-TFEA (100 nM) was added. Six hours later, cells were harvested and nuclear/cytoplasmic fractions were isolated and analysed for their levels of BACH1 and NRF2. Upper panel is a representative blot and lower panels are the quantifications of nuclear and cytoplasmic BACH1 levels normalised against their corresponding loading control. Data represent means?t?SD ( $n=$ ?3) and are expressed relative to the DMSO sample. (B) HaCaT BACH1-KO cells reconstituted with either BACH1RFP-WT or BACH1-RFP-Hemin resistant mutant were treated with DMSO $(-)$, Hemin $(10 \mu \mathrm{M})$, CDDO-Me (100 nM) or CDDO-TFEA (100 nM) for six hours. Cells were harvested and nuclear/cytoplasmic fractions were isolated and analysed for their levels of BACH1. Upper panel is a representative blot and lower panels are the quantifications of nuclear and cytoplasmic BACH1 levels normalised against their corresponding loading control. Data represent means?] [? $\mathrm{SD}(\mathrm{n}=$ ?? 3 ) and are expressed relative to their DMSO control. 
bioRxiv preprint doi: https://doi.org/10.1101/2021.10.29.466411; this version posted October 29, 2021. The copyright holder for this preprint (which was not certified by peer review) is the author/funder, who has granted bioRxiv a license to display the preprint in perpetuity. It is made available under aCC-BY 4.0 International license.

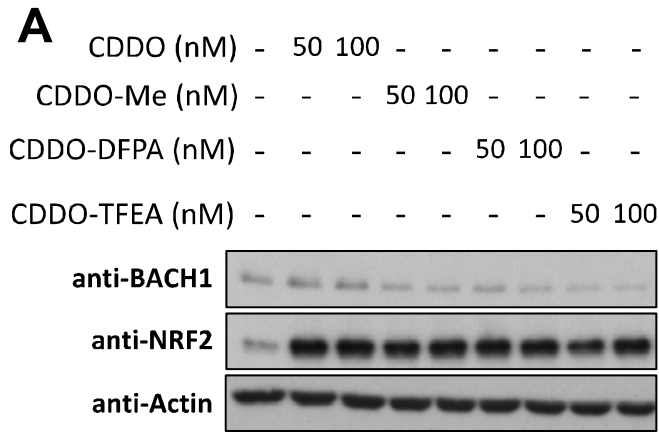

B
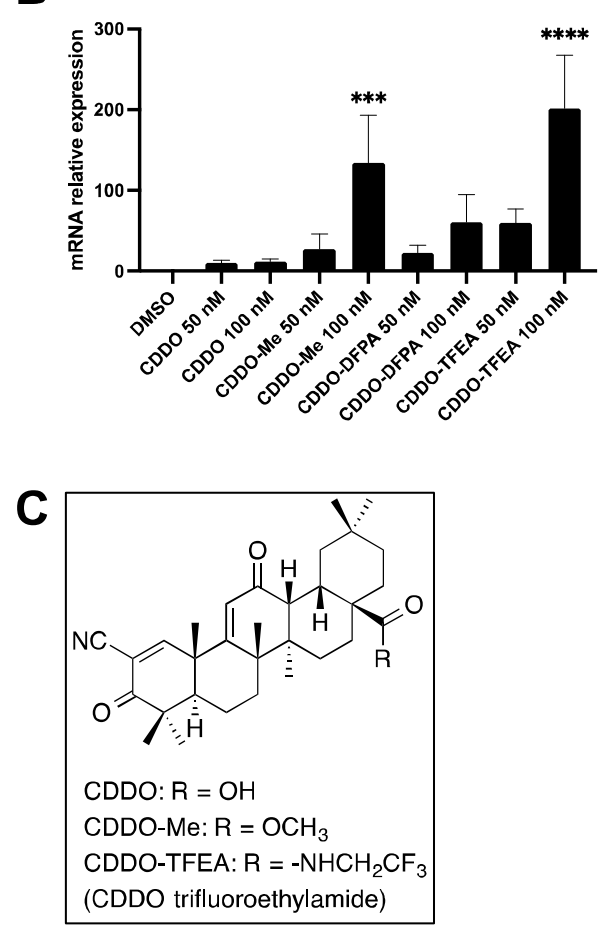

D

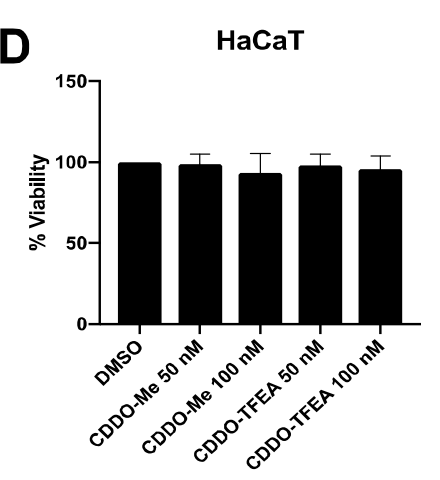

NRF2 Protein Levels

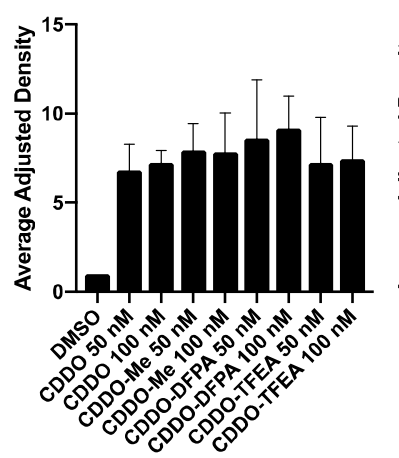

AKR1B10

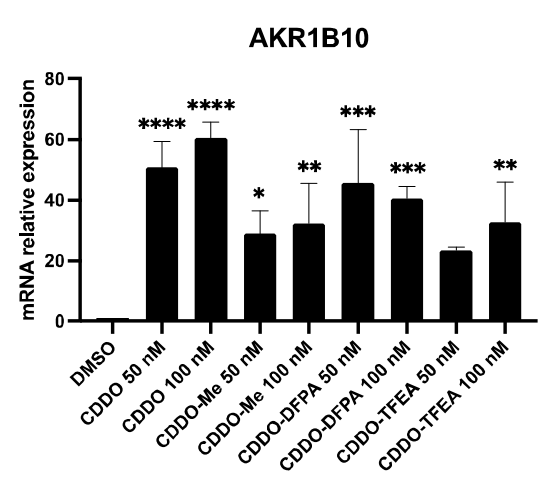

BACH1 Protein Levels

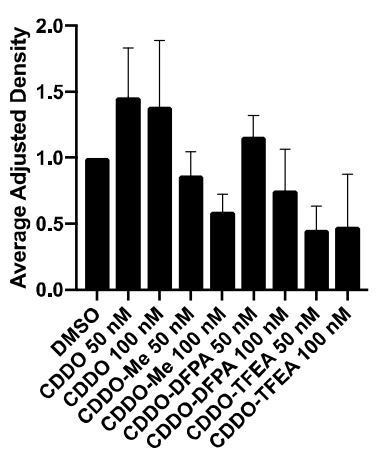

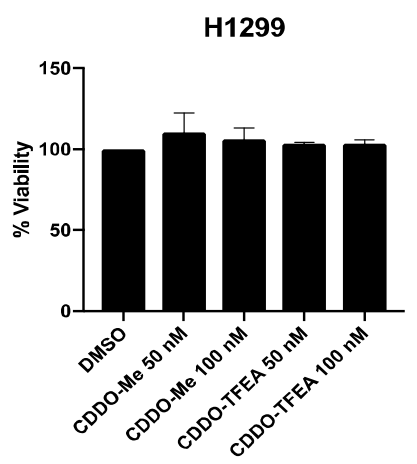

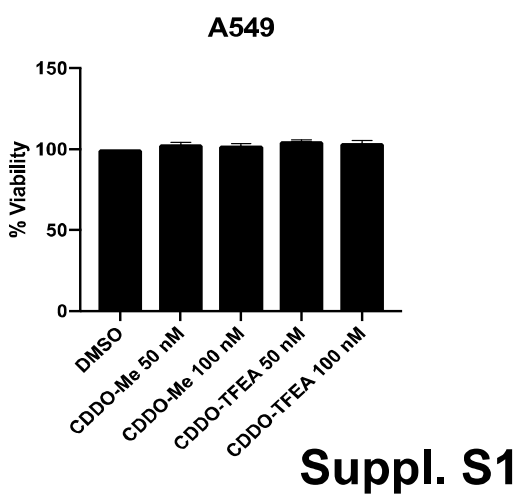

Suppl. Figure S1. (A) HaCaT cells were treated with vehicle (DMSO, $0.1 \%$, v/v) or increasing concentrations of either CDDO, CDDO-Me, CDDO-DFPA or CDDO-TFEA. After five hours cells 
were lysed and samples were analysed by Western Blot. Upper panel is a representative blot and lower panels show the quantification of BACH1 and NRF2 protein levels normalized for actin levels. Data represent means $\pm S D(n=3)$ and are expressed relative to the DMSOtreated samples. (B) HaCaT cells were treated with either DMSO $(0.1 \%, v / v)$ or different concentrations of CDDO, CDDO-Me, CDDO-DFPA or CDDO-TFEA. After 16 hours cells were harvested and lysed and mRNA levels of HMOX1 and AKR1B1O were analysed by real-time qPCR. Data were normalised using HPRT1 as an internal control $(n=3)$ and are expressed relative to the DMSO treated sample. ${ }^{*} \mathrm{P} \leq 0.05,{ }^{* * P} \leq 0.01, * * * \mathrm{P} \leq 0.001, * * * * \mathrm{P} \leq 0.0001$. (C) Structures for CDDO, CDDO-Me and CDDO-TFEA. (D) HaCaT, H1299 or A549 cells were treated with either DMSO $(0.1 \%, v / v)$ or different concentrations of CDDO-Me or CDDOTFEA as indicated. After 48 hours, viability was calculated relative to the DMSO-treated control using Alamar Blue. 
A
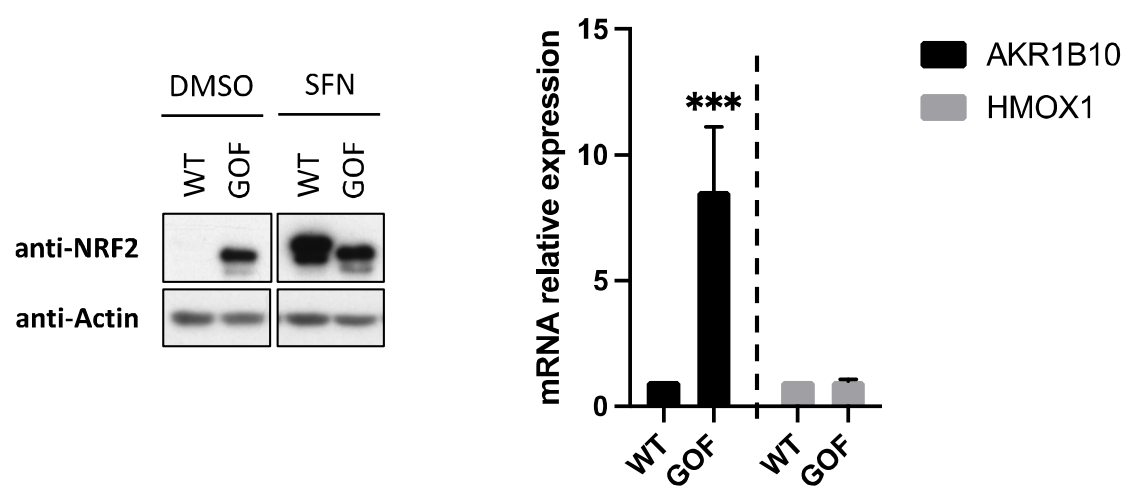

B

\section{HMOX1}

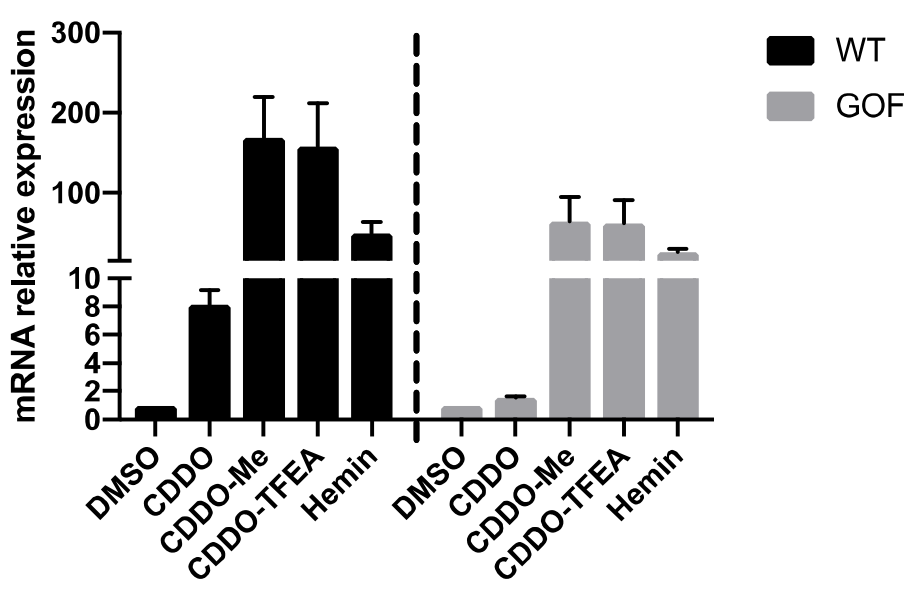

C

\section{AKR1B10}

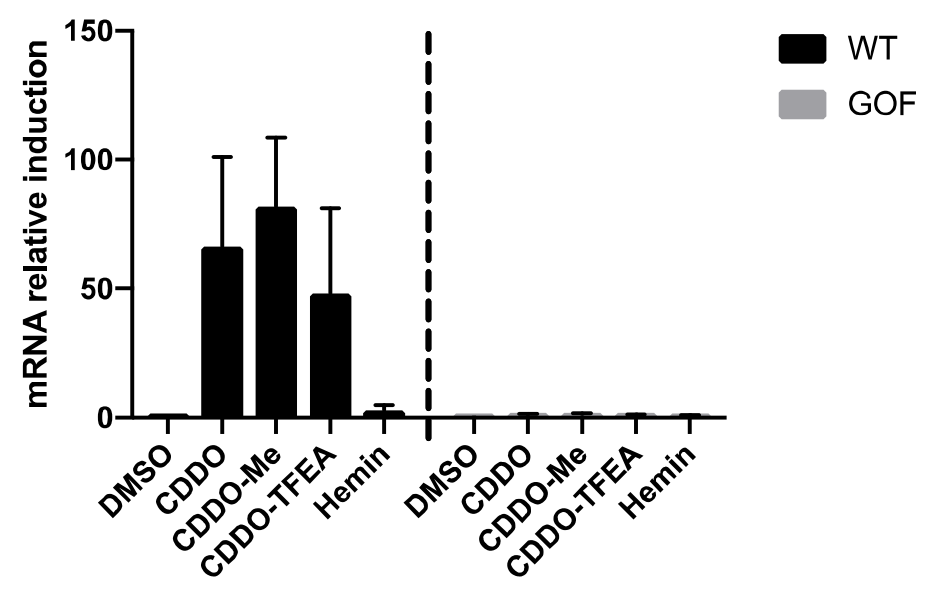

Suppl. S2

Suppl. Figure S2. (A) Left panel: Control (WT) and NRF2 gain-of-function (GOF) HK2 cells were treated with either DMSO $(0.1 \%, v / v)$ or sulforaphane (SFN). Three hours later the 
levels of NRF2 were measured by western blot. Right panel: Basal mRNA levels of HMOX1 and AKR1B10 in control (WT) and NRF2-GOF HK2 cells were analysed by RT-qPCR. HPRT1 was used as a housekeeping gene for the analysis. ***P $\leq 0.001$. (B,C) HK2 Control (WT) and NRF2-GOF cells were treated with DMSO, CDDO (100 nM), CDDO-Me (100 nM), CDDO-TFEA $(100 \mathrm{nM})$ or Hemin $(10 \mu \mathrm{M})$ for 16h. HMOX1 (B) and AKR1B10 (C) mRNA levels were analysed using RT-qPCR and HPRT1 as a housekeeping gene. Data are expressed relative to the DMSO-treated samples in each cell line (DMSO in WT and NRF2-GOF cells set to 1 ). *P $\leq$ 0.05 . 
bioRxiv preprint doi: https://doi.org/10.1101/2021.10.29.466411· this version posted October 29,2021. The copyright holder for this preprint (which was not certified by peer review) is the author/funder, who has granted bioRxiv a license to display the preprint in perpetuity. It is made available under aCC-BY 4.0 International license.

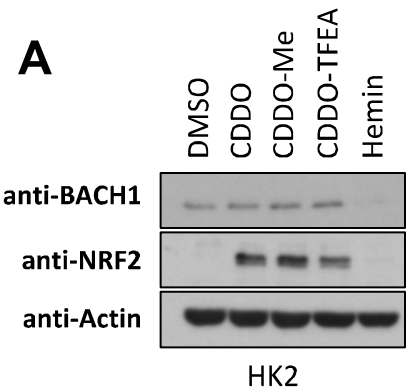

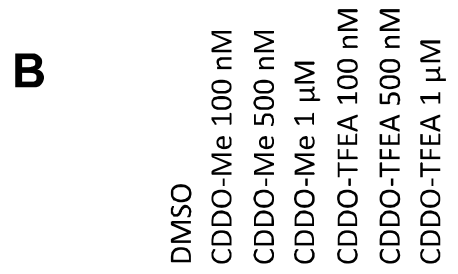
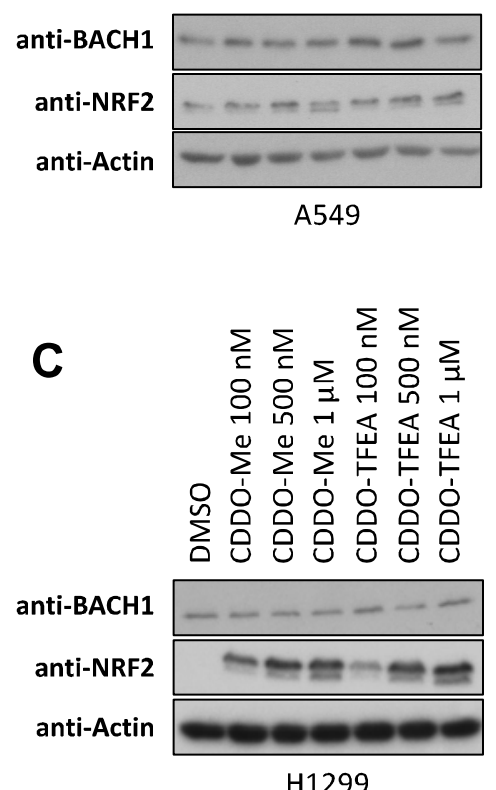

D
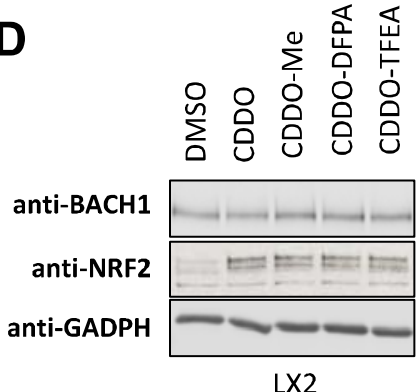

BACH1 Protein Levels

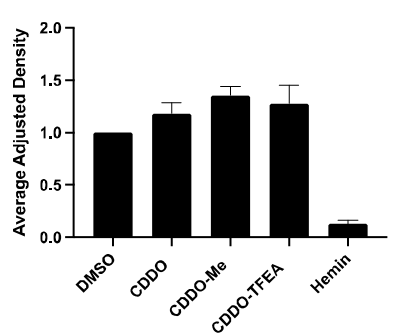

BACH1 Protein Levels

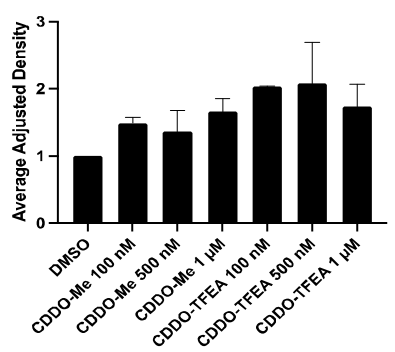

BACH1 Protein Levels

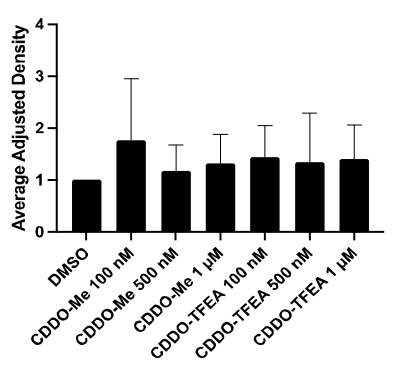

BACH1 Protein Levels

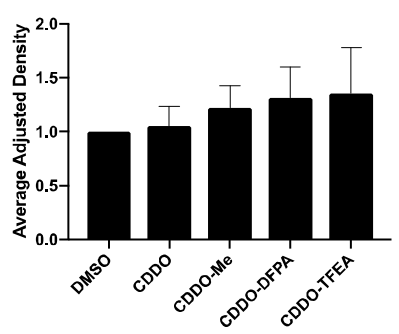

HMOX1
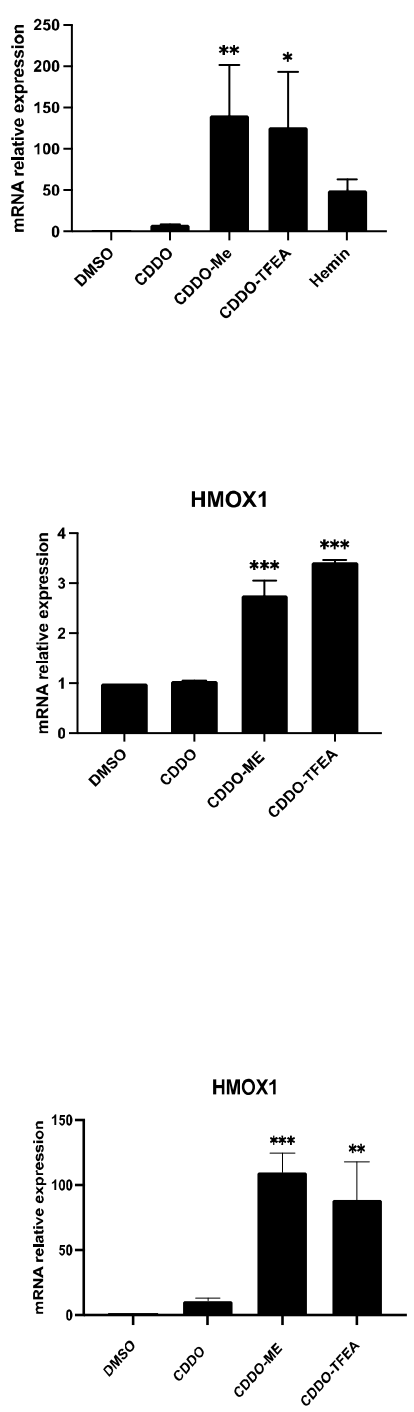

HMOX1

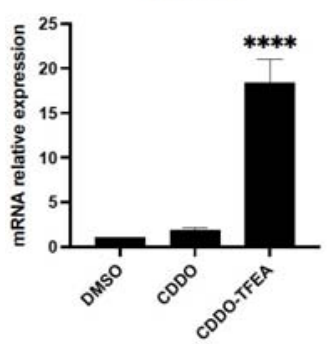

Suppl. S3 
bioRxiv preprint doi: https://doi.org/10.1101/2021.10.29.466411. this version posted October 29,2021. The copyright holder for this preprint (which was not certified by peer review) is the author/funder, who has granted bioRxiv a license to display the preprint in perpetuity. It is made available under aCC-BY 4.0 International license.

$\mathbf{E}$
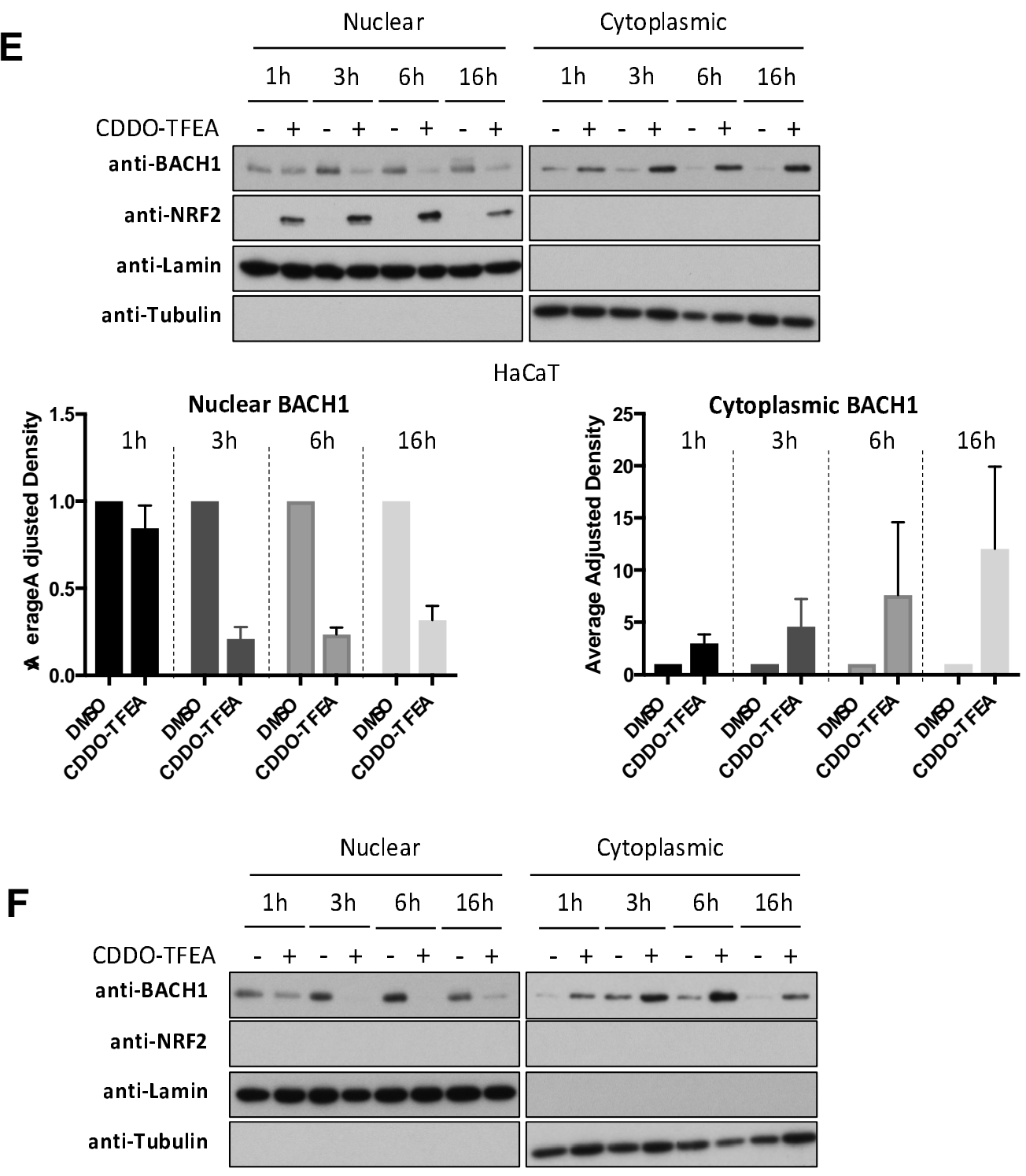

HaCaT NRF2-KO
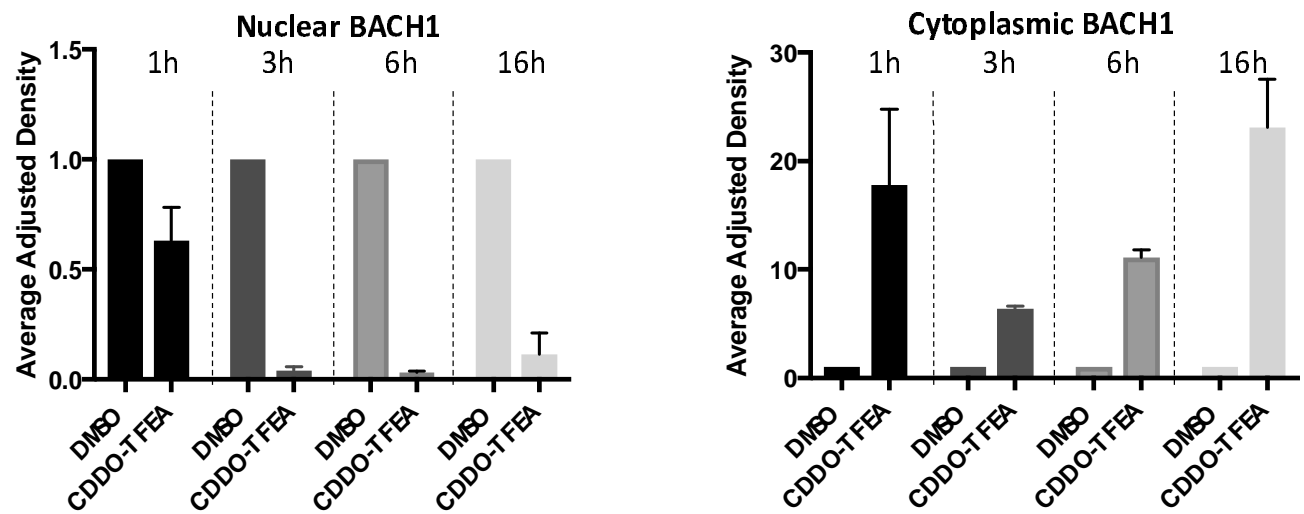

Suppl. S3 


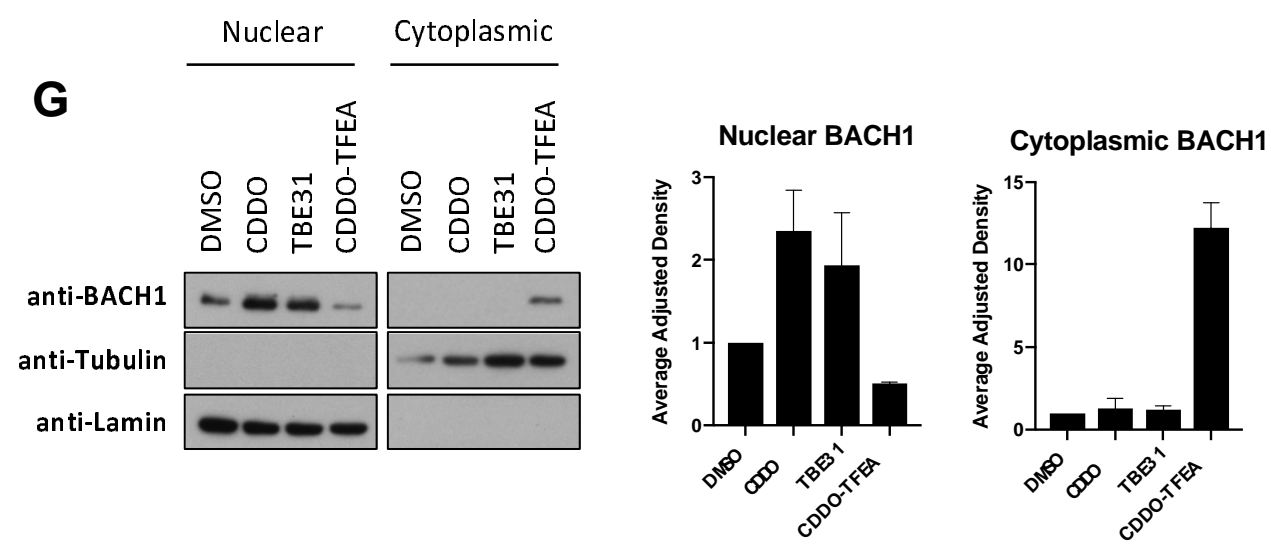

\section{Suppl. S3}

Suppl. Figure S3. (A) HK2 cells were treated with DMSO, CDDO (100 nM), CDDO-Me (100 $\mathrm{nM}), \mathrm{CDDO}-\mathrm{TFEA}(100 \mathrm{nM})$ or hemin $(10 \mu \mathrm{M})$ for $6 \mathrm{~h}$. Cells were lysed and total BACH1, NRF2 and actin levels were analysed by western blot. Representative blot is shown on the left panel and quantification of BACH1 protein levels $(n=2)$ is in the middle panel. Right panel: HK2 cells were treated with either DMSO $(0.1 \%, v / v)$, CDDO (100 nM), CDDO-Me (100 nM), CDDO-TFEA (100 nM) or hemin $(10 \mu \mathrm{M})$ for $16 \mathrm{~h}$. HMOX1 mRNA levels were analysed. ${ }^{*} \mathrm{P} \leq$ $0.05, * * \mathrm{P} \leq 0.01$. (B) A549 cells were treated with DMSO $(0.1 \%, v / v)$ or increasing concentrations of CDDO-Me or CDDO-TFEA for 6h. Left panel shows a representative blot while middle panels show quantification of BACH1 protein levels $(n=2)$. Right panel: A549 cells were treated with DMSO $(0.1 \%, v / v)$, CDDO (100 nM), CDDO-Me (100 nM) or CDDOTFEA (100 nM) for 6h. HMOX1 mRNA levels were analysed. ***P $\leq 0.001$ (C) H1299 cells were treated with DMSO $(0.1 \%, v / v)$ or increasing concentrations of CDDO-Me or CDDOTFEA for 16h. Left panel shows a representative blot while middle panels show quantification of BACH1 protein levels ( $n=2)$. Right panel: H1299 were treated with DMSO (0.1\%, v/v), CDDO (100 nM), CDDO-Me (100 nM) or CDDO-TFEA (100 nM) for 16h. HMOX1 mRNA levels were analysed. $* * \mathrm{P} \leq 0.01, * * * \mathrm{P} \leq 0.001$. (D) $\mathrm{LX} 2$ cells were treated with DMSO 
(0.1\%, v/v), CDDO (50 nM), CDDO-Me (50 nM), CDDO-DFPA (50 nM) or CDDO-TFEA (50 nM)

for 6h. Samples were lysed and total BACH1, NRF2 and ACTIN levels were analysed by western blot. Representative blot is shown on the left panel and quantification of BACH1 protein levels $(n=3)$ is in the middle panel. Right panel: LX2 cells were treated with either DMSO $(0.1 \%, v / v)$, CDDO (50 nM) or CDDO-TFEA (50 nM) for 16h. HMOX1 mRNA levels were analysed. ${ }^{*} \mathrm{P} \leq 0.05, * * P \leq 0.01$. (E,F) HaCaT WT cells $(\mathrm{E})$ and NRF2-KO cells $(\mathrm{F})$ were treated with DMSO $(0.1 \%, v / v)$ or CDDO-TFEA $(100 \mathrm{nM})$ for $1 \mathrm{~h}, 3 \mathrm{~h}, 6 \mathrm{~h}$ or $16 \mathrm{~h}$. Cells were harvested and nuclear and cytosolic fractions were isolated and analysed for the levels of the indicated proteins. Upper panel is a representative blot; lower panels are the quantification of BACH1 nuclear and cytoplasmic levels $(n=2)$. Data are expressed relative to the DMSO-treated samples for each time point and were normalized against their respective loading controls (DMSO sample for each time point set to 1). (G) HaCaT WT cells were treated with either DMSO $(0.1 \%, v / v)$, CDDO (100 nM), TBE-31 (100 nM) or CDDO-TFEA (100 nM) for six hours. Nuclear and cytosolic fractions were isolated and analysed for their levels of BACH1. Upper panel is a representative blot and lower panels show the quantification of BACH1 nuclear and cytoplasmic levels $(n=2)$, normalized against their respective loading controls. Data is expressed relative to the DMSO treated samples. 
bioRxiv preprint doi: https://doi.org/10.1101/2021.10.29.466411; this version posted October 29, 2021. The copyright holder for this preprint (which was not certified by peer review) is the author/funder, who has granted bioRxiv a license to display the preprint in perpetuity. It is made available under aCC-BY 4.0 International license. 
bioRxiv preprint doi: https://doi org/10.1101/2021.10 29.466411. this version posted October 292021 The copyright holder for this preprint (which was not certified by peer review) is the author/funder, who has granted bioRxiv a license to display the preprint in perpetuity. It is made available under aCC-BY 4.0 International license.

A

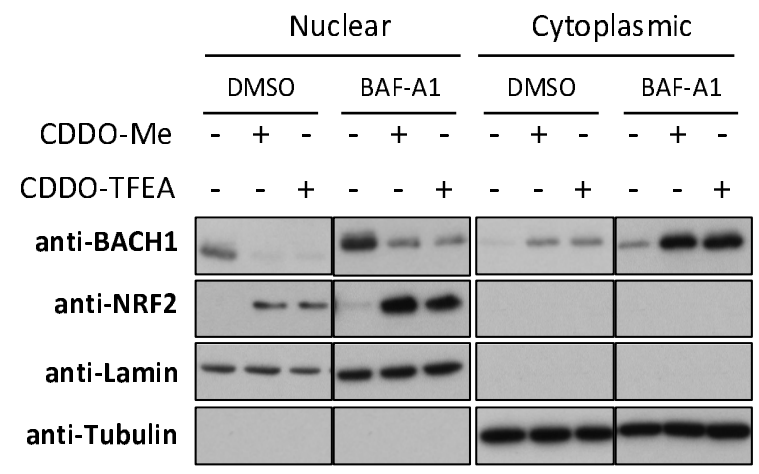

Nuclear BACH1

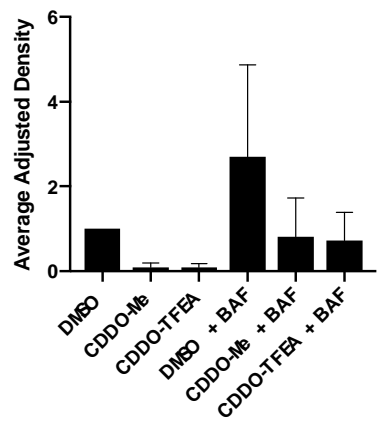

Cytoplasmic BACH1

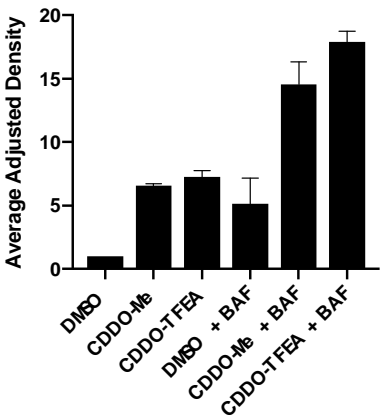

B

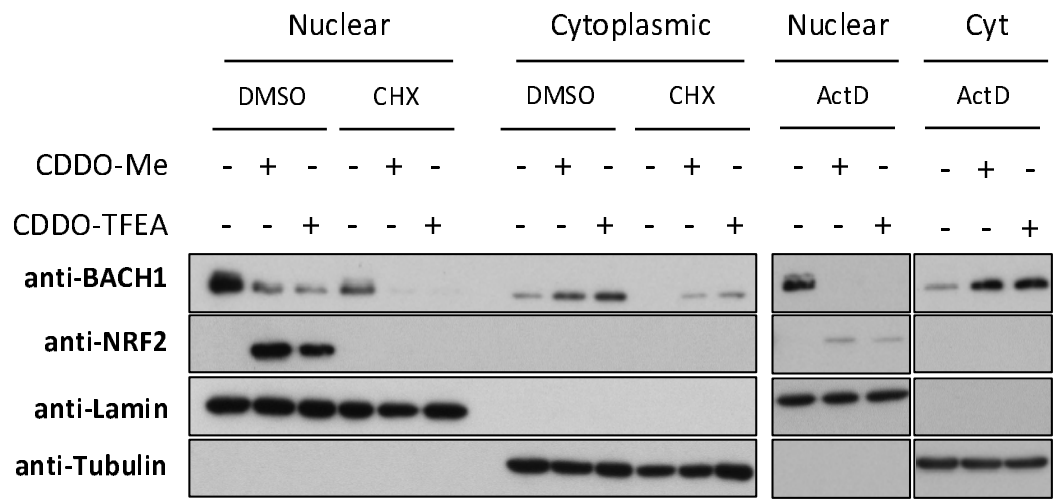

Nuclear BACH1

Cytoplasmic BACH1
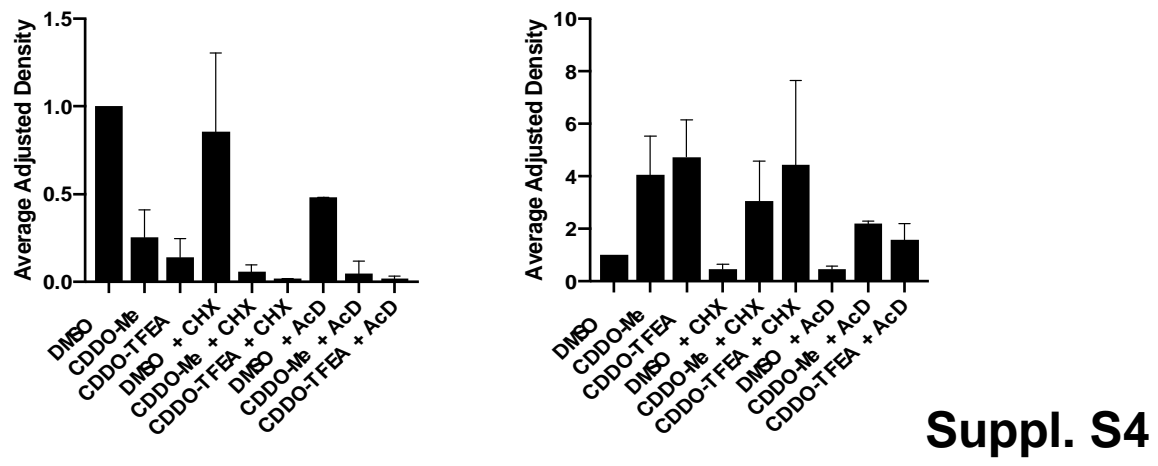


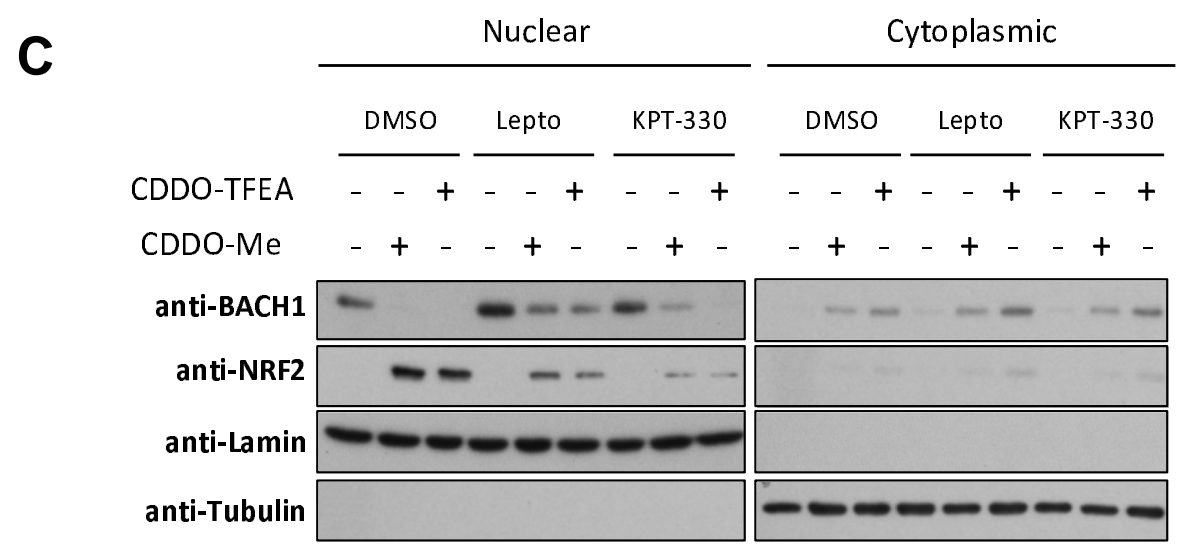

\section{Nuclear BACH1}

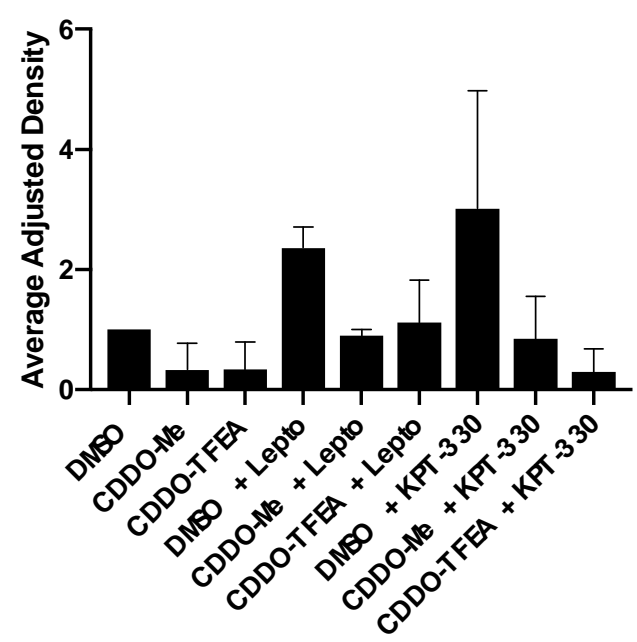

Cytoplasmic BACH1

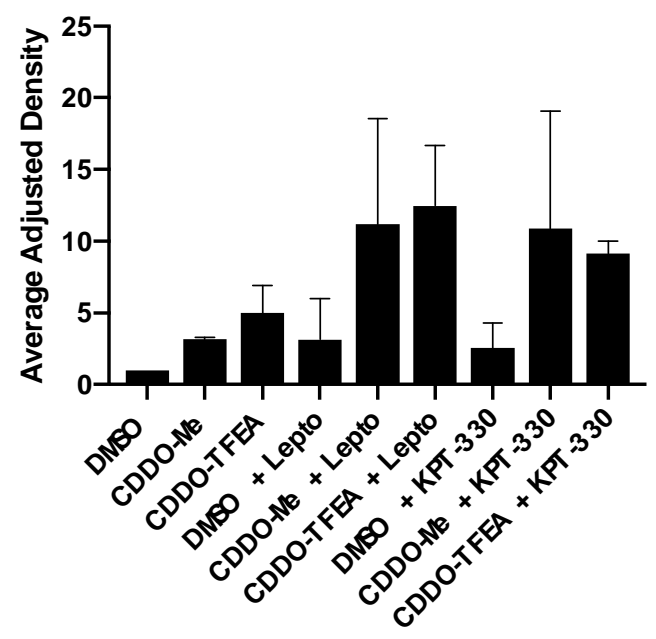

Suppl. S4

Suppl. Figure S4. (A) HaCaT cells were incubated with either DMSO $(0.1 \%, v / v)$ or bafilomycin A1 (BAF-A1, $100 \mathrm{nM})$. Two hours later they were treated with either DMSO (-), CDDO-Me (100 nM) or CDDO-TFEA (100 nM) for another six hours. Subcellular fractionation was performed as previously described. Upper panel is a representative blot and lower panels are the quantifications of nuclear and cytoplasmic $\mathrm{BACH} 1$ levels normalised against their corresponding loading control. Data represent means? + ? $S D(n=$ ? 2$)$ and are expressed relative to the DMSO sample. Control and BAF-A1 treated samples were all loaded in the same gel (B) HaCaT cells were incubated with either DMSO $(0.1 \%, v / v)$, cycloheximide (CHX, $10 \mu \mathrm{M})$ for $2 \mathrm{~h}$ or actinomycin $\mathrm{D}($ ActD, $1 \mu \mathrm{g} / \mathrm{mL})$ for $30 \mathrm{~min}$. After that, either DMSO (-), 
CDDO-Me (100 nM) or CDDO-TFEA (100 nM) was added. Six hours later, cells were harvested and nuclear/cytoplasmic fractions were isolated and analysed for their levels of $\mathrm{BACH} 1$ and NRF2. Upper panel is a representative blot; lower panels are the quantifications of nuclear and cytoplasmic BACH1 levels normalised against their corresponding loading control. Data represent means? \pm ? SSD $(n=$ ?3) and are expressed relative to the DMSOtreated cells. (C) HaCaT cells were incubated with either DMSO $(0.1 \%, v / v)$, leptomycin B (Lepto, $25 \mathrm{ng} / \mathrm{mL}$ ) or KPT-330 (1 $\mu \mathrm{M})$. After two hours, either DMSO (-), CDDO-Me (100 nM) or CDDO-TFEA (100 nM) was added. Six hours later, cells were harvested and subcellular fractionation was performed. BACH1 and NRF2 protein levels were analysed by western blot. Upper panel is a representative blot and lower panels are the quantification of BACH1 nuclear and cytoplasmic levels normalised to the corresponding loading control. Data represent means? 1 ? SD $(n=3)$ and are expressed relative to the DMSO-treated cells. 